\title{
A STORMWATER MANAGEMENT MODEL FOR CALIFORNIA POLYTECHNIC STATE UNIVERSITY CAMPUS
}

\author{
A Thesis \\ Presented to \\ The Faculty of California Polytechnic State University, \\ San Luis Obispo
}

In Partial Fulfillment of the Requirement for the Degree Master of Science in Civil Engineering

By

Hsuan-Wen Chu

December 2018 
(C)2018

Hsuan-Wen Chu

ALL RIGHTS RESERVED 


\section{COMMITTEE MEMBERSHIP}

TITLE: A Stormwater Management Model for California Polytechnic State University Campus

AUTHOR: Hsuan-Wen Chu

DATE SUBMITTED: December 2018

COMMITTEE CHAIR: Misgana Muleta, Ph.D.

Professor of Civil Engineering

COMMITTEE MEMBER: Shikha Rahman, Ph.D.

Professor of Civil Engineering

COMMITTEE MEMBER: Rebekah Oulton, Ph.D.

Assistant Professor of Civil Engineering 


\section{ABSTRACT}

A Stormwater Management Model for California Polytechnic State University Campus

\section{Hsuan-Wen Chu}

Developments that have been taking place on Cal Poly campus over the years have altered the natural hydrology of the area. Stormwater management practices could help reduce the impacts of these developments. Computer models can help to design effective and economical stormwater management solutions at a watershed scale. As such, the objective of this study was to develop a stormwater management model for Cal Poly campus. The model was developed based on the utility data obtained from the university and other watershed data available from open sources. Field surveys were conducted to address some anomalies in the utility data, and streamflow monitoring was performed. The model was calibrated using the streamflow data measured during this study. The calibration effort significantly improved the prediction accuracy of the model. The calibrated model was then used to analyze the hydrologic performance of implementing LID systems for two projects that Cal Poly plans to build. Permeable Pavements (PPs) and Bioretention Cells (BRCs) were the LID types examined. The LIDs were evaluated based on peak flow and runoff volume reductions they would achieve. The potential reductions were compared for current conditions and the proposed project if LIDs were implemented, and for inflows to the LIDs and outflows from the LIDs. The results indicate that implementing a PP system for the proposed student apartment at the current $\mathrm{H}-1$ and $\mathrm{R}-1$ parking lots and a BRC system for the proposed engineering project facilities at the current $\mathrm{H}-2$ parking lots will significantly reduce peak flow and runoff volume. Overall, the developed model will help the university with the traditional stormwater management practices such as flood control and to identify effective LID practices for future developments. Limitations of the current model and recommendations on how to improve the model are also discussed.

Keywords: [PCSWMM, Stormwater management, Low Impact Development, Permeable Pavement, Bioretention Cell, Watershed Delineation] 


\section{ACKNOWLEDGMENTS}

I am enormously grateful to my thesis advisor, Dr. Muleta, for his continuous support. Muleta's dedication to high professional standards and knowledge of hydrologic modeling has been a tremendous inspiration throughout my thesis development.

I thank the members of my committee: Dr. Oulton and Dr. Rahman. I truly enjoyed the conversations with them, and they were very responsive when I had any questions.

I want to thank Austin McCollum, Joel Scianna, Simon Poon, and Matthew Guevara. Mr. McCollum's pilot study on developing SWMM model for a small area on Cal Poly campus provided very useful information. Mr. Scianna, Mr. Poon, and Mr. Guervara provided generous support when I faced challenges on this journey.

I would like to thank Mrs. Porter and Mr. Weber for providing useful data. Also, I would like to thank Dr. Rogers, Dr. Surfleet, Professor Derbidge, Mr. White, and Mr. Bodermer for providing useful information and giving me direction on my thesis development.

I am extremely grateful for the PCSWMM license provided by Computational Hydraulics International $(\mathrm{CHI})$. This study would not have been possible without their help with the software.

Lastly, I truly thank my family for their continued support along the way: my mother, my father, my younger brother, my grandmother, my aunts and uncles. 


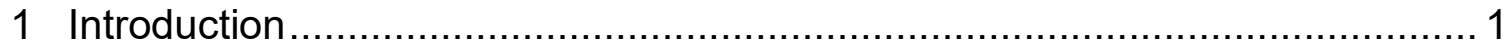

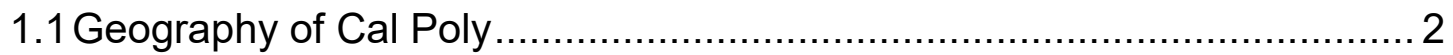

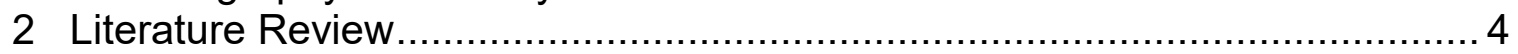

2.1 Hydrologic Impacts of Urbanization ............................................... 4

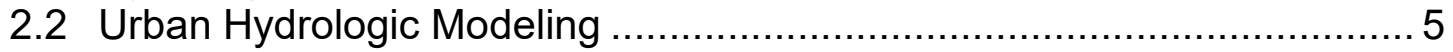

2.3 Urban Stormwater Models and Model Selection.................................. 5

2.4 Urban Watershed Delineation..................................................... 7

2.5 Importance of Model Calibration ....................................................... 8

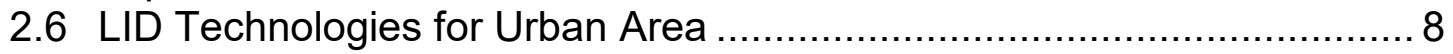

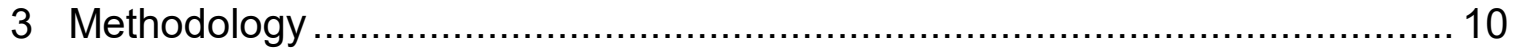

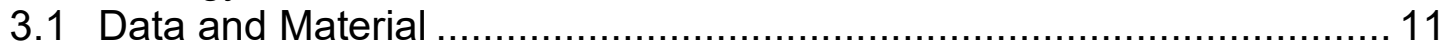

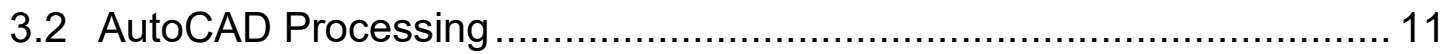

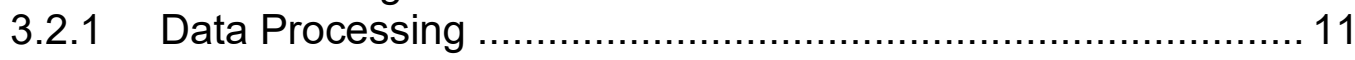

3.2.2 Field Survey ............................................................ 12

3.3 ArcMap Processing …........................................................... 14

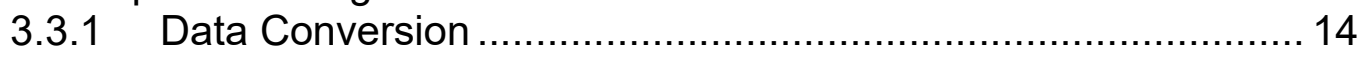

3.3.2 Land Information Extraction .............................................. 14

3.3.3 Subcatchment Outside of the One-meter DEM Boundary ........ 16

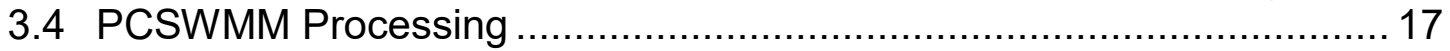

3.4.1 Watershed Delineation Tool.............................................. 17

3.4.2 Assigning Conduit Information ............................................ 20

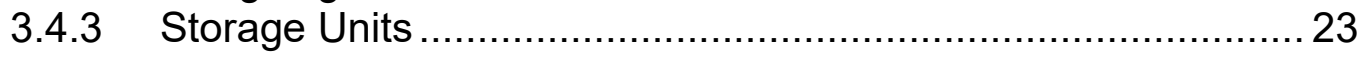

3.4.4 Pipe Profile Adjustment....................................................... 25

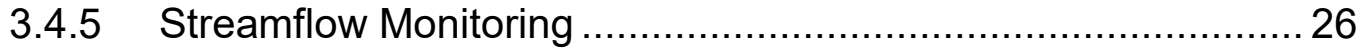

3.4.6 Subcatchment and Conduit Parameters ................................ 31

3.4.7 Model Calibration ............................................................. 35

3.4.8 LID Simulation for the Engineering Project Facilities and New Student Housing ................................................................... 36

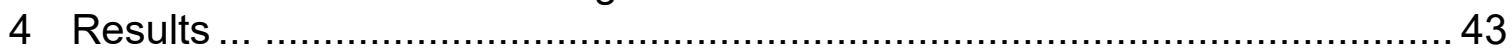

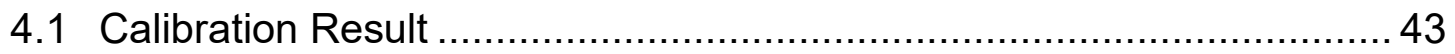

4.2 LID Simulation Results ............................................................. 46

4.2.1 BRC Simulation - Engineering Project Facilities ......................4 47

4.2.2 PPs Simulation - Engineering Project Facilities ...................... 50

4.2.3 RC simulation - New Student Housing ................................ 54

4.2.4 PPs Simulation - New Student Housing ................................. 56

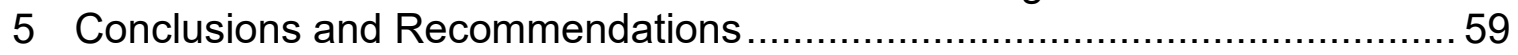

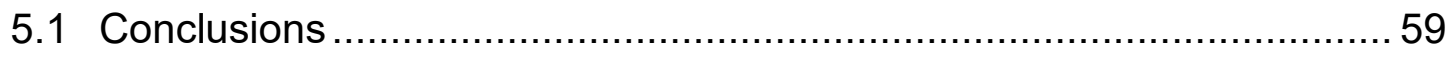

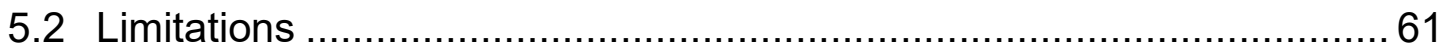

5.2.1 Recommendations for Future Research ................................ 63

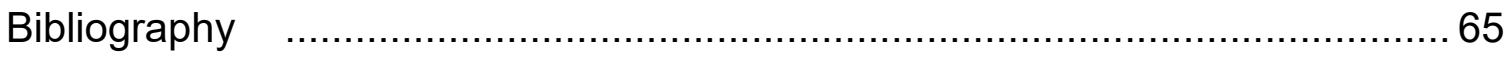




\section{LIST OF TABLES}

Table

Page

1. The information about the reservoir systems at Cal Poly ........................... 25

2. Manning's $n$ value for different land use types (McCuen, R. et al., 1996)....... 32

3. Manning's $\mathrm{N}$ value for channels (ASCE, 1982).......................................... 34

4. Manning's $n$ valve for various pipe materials (Caltrans, 2014) ..................... 34

5. Depression storage for different types of surfaces (ASCE 1992) ................. 35

6. LID parameters for SWMM modeling - BRC (Rossman, \& Huber, 2016) ...... 40

7. LID parameters for SWMM modeling - PPs (Rossman, \& Huber, 2016) ....... 41

8. The error statistics derived from measured and simulated streamflow.......... 44

9. Comparison of the observed and predicted streamflow.............................. 46

10. Comparison of the observed and predicted streamflow.............................. 46

11. The peak flow and total inflow volume of the current site condition (Current for SA) and proposed site condition (Isolated LID) ....................... 48

12. The inflow (S-SEP) and outflow (S-EFP-1) through the BRC ..................... 49

13. The peak flow reduction rate by implementing RGs or BRCs through field

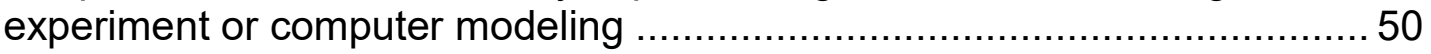

14. The runoff volume reduction rate by implementing RGs or BRCs through field experiment or computer modeling ................................................ 50

15. The peak flow and total inflow volume of the current site condition (Correction of Current Condition) and the proposed site condition

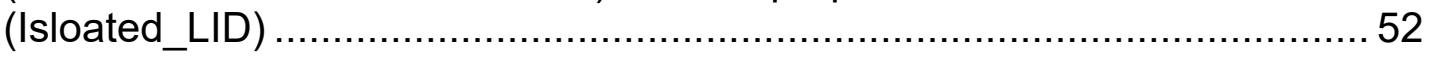

16. The inflow (S-SEP) and outflow (S-EFP-1) through the PPs ..................... 53

17. The values of runoff volume and peak flow reduction rate by implementing PPs through field experiment and computer modeling

18. The runoff and total inflow of the current condition (Current for SA) and

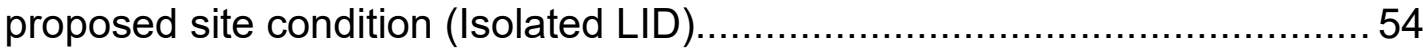

19. The inflow (S-SA) and outflow (S-SA-1) through the BRCs.......................55

20. The runoff and total inflow of the current site condition (Current for SA) and proposed site condition (Isolated LID)...........................................5 57

21. The table of the inflow (S-SA) and outflow (S-SA-1) through the PPs .........55

22. The top four subcatcments with the highest percent imperviousness 62 


\section{LIST OF FIGURES}

Figure $\quad$ Page

1. The illustration of Cal Poly Campus and Ranches (Cal Poly, 2015) ................ 3

2. Hydrologic Impacts of urbanization at the catchment scale (Flectcher, Andrieu, \& Hamel, 2013) ................................................................ 5

3. Major Tools Used \& Analysis Performed to Develop the SWMM Model......... 10

4. Details of the storm sewer layers obtained in AutoCAD format ..................... 12

5. A trench drain in the utility file ................................................................ 13

6. A trench drain on Cal Poly campus ........................................................ 14

7. The watershed delineation result of the City of San Luis Obispo................... 16

8. The delineation result of subcatchments that were outside of the one-meter DEM boundary (Blue Polygon). The straight line crossed the campus boundary indicated the edge between one-meter and five-meter DEM, and the hatched polygons with red lines indicated the subcatchments outside of the one-meter DEM border.............................................................. 17

9. Multiple subcatchments were merged by using the join command if they shared the same outlet. The red dash-lines indicated the outlet junctions of each subcatchment

10. The sewer network located near Cerro Vista Circle student apartment did not have pipe diameter information in the utility file. .................................2. 21

11. Unrealistic cross-section created by PCSWMM for one of the conduits. ...... 22

12. A corrected transect for the conduit.................................................... 22

13. A storage curve for a storage unit...................................................... 24

14. The location of reservoirs within the San Luis Obispo Creek watershed ...... 25

15. The profile of a conduit/junction path................................................... 26

16. Streamflow monitoring Locations......................................................... 28

17. One of the monitoring sites at Brizzolara creek during the rain event on

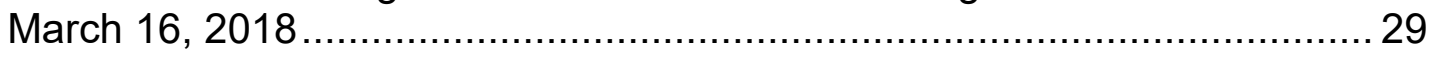

18. A 100 feet cloth tape stretched across the channel during one of the monitoring efforts. ........................................................................ 29

19. A Hack flow meter was used to measure the current in the river................. 30

20. The Excel spreadsheet with the observed data on March $21 \ldots \ldots \ldots \ldots \ldots \ldots \ldots . . . . . .30$

21. Google Earth was used to identify the distribution of various land uses within the campus boundary. The green polygons are subcatchments. ...... 32

22. The time series data from CIMIS ..................................................... 36

23. The typical cross-section of a BRC (Rossman, \& Huber, 2016) ................. 38

24. The typical detail of permeable pavements (Virginia DEQ, 2011) ................ 39

25. Proposed project site for Engineering Project Facilities was drained to the LID subcatchment which was separated from the project site …................ 42

26. Streamflow time series at the monitoring site before calibration................. 44

27. Streamflow time series at the monitoring site after calibration..................... 44

28. The inflow of the current site condition (Current for SA) and the master plan condition (Isolated LID) ........................................................... 49

29. The inflow (S-SEP) and outflow (S-EFP-1) through the BRC .................... 49 
30. The peak flow and total inflow volume of the current site condition (Correction of Current Condition) and the proposed site condition (Isloated_LID)

31. The inflow (S-SEP) and outflow (S-EFP-1) through the PPs.................... 53

32. The runoff and total inflow of the current condition (Current for SA) and proposed site condition (Isolated LID)

33. The inflow (S-SA) and outflow (S-SA-1) through the BRCs.

34. The runoff and total inflow of the current site condition (Current for SA) and proposed site condition (Isolated LID)....

35. The graph of the inflow (S-SA) and outflow (S-SA-1) through the PPs........ 58 


\section{Introduction}

California Polytechnic State University (Cal Poly) is a public education institution founded in 1901. Over the last 100 years, the campus core has experienced dramatic land cover change as educational buildings, parking lots, and oncampus student housings were built. These land cover changes alter natural hydrology of the area including increasing in runoff volume and peak flow rates, the degradation of water quality, and the modification or destruction of habitats (Mishra, 2012).

Low impact developments (LIDs) are often used to mitigate the impact of urban developments on the natural environment. They were first applied by the County of Prince George in Maryland in the early 1990's. LIDs strive to mimic natural hydrology of the area to minimize and potentially diminish the impacts of urban development on runoff quantity and quality, and the destruction of environmentally sensitive sites (USEPA, 2000). Research has shown that LIDs can be very effective to decrease surface runoff, improve water quality, reduce erosion and sedimentation of natural waterways, and lower peak discharge (Kong, Ban, Yin, James, \& Dronova, 2017).

LIDs can be designed and analyzed on a site-by-site basis or at a watershed scale. Watershed scale designs are recommended as they could be more economical as well as effective in reducing the impacts of developments. Computer models are often needed to facilitate watershed scale design of LIDs (Muleta, Mcmillan, Amenu, \& Burian, 2013). A watershed model can provide 
valuable information regarding the relationship between hydrological characteristics and runoff quantity and quality generated during various storm events, which can lead to success in creating cost-effective LID strategies (Barich, 2014). Currently, Cal Poly does not have a completed stormwater management model to simulate the performance of proposed or existing LIDs, even though many LID devices have been installed to treat stormwater especially from the new buildings and parking lots. As such, the objectives of this study are: To develop a stormwater management model for Cal Poly campus.

To evaluate the hydrologic performance of LIDs using the developed stormwater management model.

\subsection{Geography of Cal Poly}

Cal Poly is located in the City of San Luis Obispo halfway between San Francisco and Los Angeles. Cal Poly's land consists of the main campus and six ranches with a total approximate area of 6,000 acres. The main campus is divided into two watersheds: San Luis Obispo Creek and Chorro Creek watersheds. For this study, the San Luis Obispo Creek watershed, a 2,942.4 acres land composed of the campus core, Serrano ranch, Peterson ranch, and Cheda ranch were selected. The San Luis Obispo Creek watershed was selected because it is where most developments and stormwater infrastructures exist. Figure 1 illustrates Cal Poly campus and ranches. 


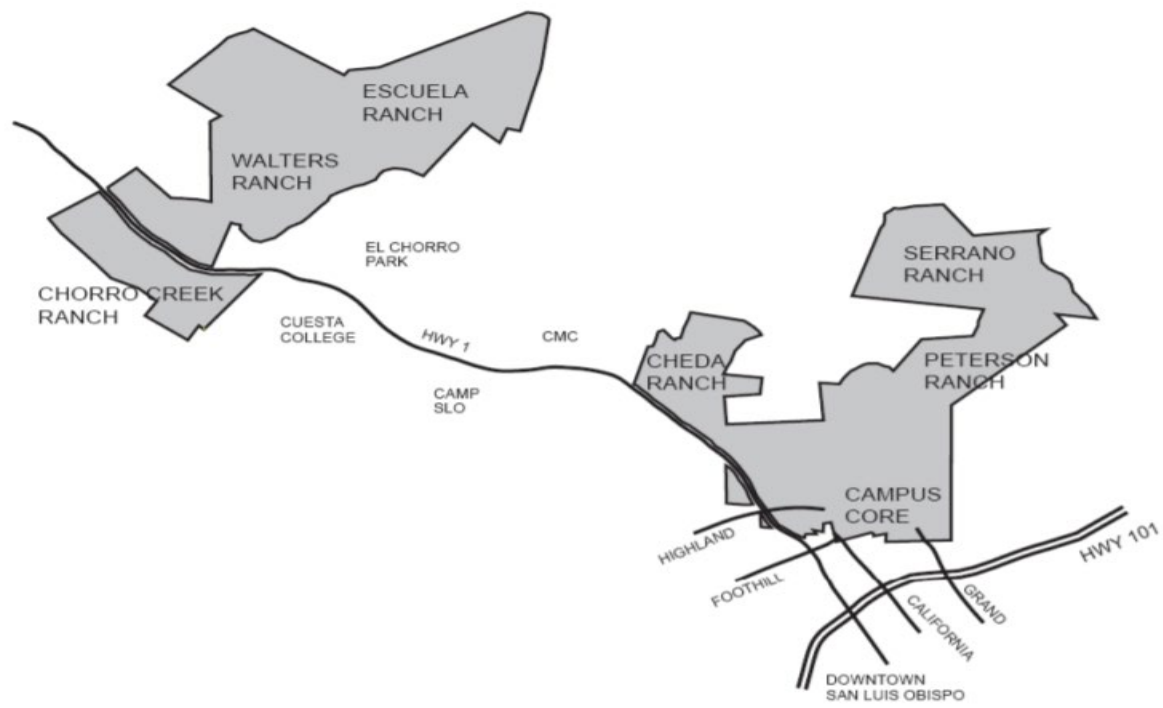

Figure 1 The illustration of Cal Poly Campus and Ranches (Cal Poly, 2015) 


\section{Literature Review}

\subsection{Hydrologic Impacts of Urbanization}

Rain that falls on a pervious land either infiltrates the soil or becomes runoff. For impervious areas, almost all the rain become surface runoff that carries a variety of substances into watercourses such as streams that could negatively impact stream ecology and water quality. Flectcher, Andrieu, and Hamel (2013) reported that drainage structures such as storm networks, sewer pipes, and man-made channels are very concentrated in urban areas. Increases in imperviousness and the density of sewer systems increase runoff volume and peak discharge, and decrease the lag time (Zoppou, 2000), and lead to the degradation of stream ecosystems. Figure 2 illustrates the hydrologic impacts of urbanization.

Flectcher, Andrieu, and Hamel (2013) also summarized previous studies and concluded that the ecological richness of urban waters is usually low. They observed that the percentage of directly connected imperviousness, which is the impervious surface connected with the drainage network to water bodies, is among the major causes of urban river degradation. 


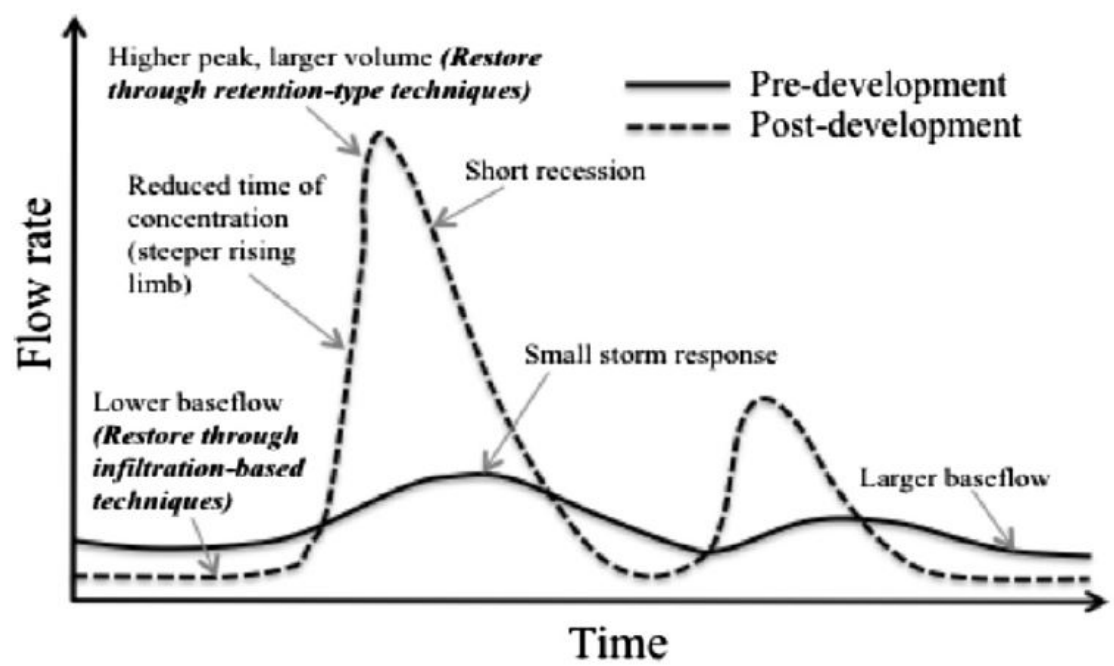

Figure 2 Hydrologic Impacts of urbanization at the catchment scale (Flectcher, Andrieu, \& Hamel, 2013)

\subsection{Urban Hydrologic Modeling}

Research in urban hydrology has focused on ways to manage stormwater in urban areas to prevent flooding, improve public health, and protect ecosystems. Management of stormwater in urban settings requires innovative approaches to predict as well as reduce impacts of stormwater. Modeling at detailed temporal and spatial scale is required to simulate impacts on receiving water bodies due to fast response of urban catchments. Demands in stormwater modeling have led to the development of a variety of urban stormwater models (Flectcher, Andrieu, \& Hamel, 2013). Selecting a suitable model that fits the objectives of a study is imperative.

\subsection{Urban Stormwater Models and Model Selection}

Many programs have been developed for stormwater modeling. Some of the models are focused on rural areas, and some are mainly used for urban settings. Model for Urban Sewer (MOUSE) and SWMM are the two most versatile urban stormwater models that could be used for a wide range of applications. They 
both adequately predict runoff from small catchments since they allow sub-hourly time steps to characterize fast response of urban catchments. Simulating at subhourly time steps is important for LID analysis as it could capture the relationship between runoff and the associated treatment processes the LIDs use. Thus, MOUSE and SWMM are considered suitable to model LID devices (Elliott \& Trowsdale, 2007).

Modeling water quality and pollutant buildup/transport are also important criteria for urban hydrology models. Models such as the Model for Urban Stormwater Treatment Devices (MUSIC) and SWMM have features to simulate water quality improvement by LIDs and pollutant loads during rain events (Flectcher, Andrieu, \& Hamel, 2013). SWMM can simulate both water quality and quantity of surface runoff and pipe flow from both continuous and single rain events. LID control module was also added to SWMM to simulate the performance of devices such as rain gardens and permeable pavements. In SWMM, LID devices are simulated as multiple vertical layers whose properties such as porosity, conductivity, thickness, and seepage rate are characterized on a per-unit-area basis (Palla \& Gnecco, 2015).

EPA SWMM is one of the most popular computer-based stormwater models among professionals and researchers (Jayasooriya \& Ng, 2014). PCSWMM, a proprietary software application that supports all the functionalities of EPA 
SWMM plus more tools, and also provides compatibility with GIS software was selected for this study.

\subsection{Urban Watershed Delineation}

A watershed, also known as a drainage basin, is an area of land where precipitation falls on the land and is directed to an outlet. Watershed delineation is the first step in building a hydrologic model, and accurate watershed delineation is crucial for successful modeling. An urban hydrologic system consists of a stormwater conveyance infrastructure including drainage systems, overland flow paths, and stormwater intakes that connect surface and subsurface flows. These three components must be considered when processing an urban watershed delineation that represents a complex urban environment.

Tikkanen (2013) discussed a methodology that takes stormwater intakes and drainage network into account for watershed delineation. The study combined the stormwater network with the stream dataset to create a combined network and applied stream "burning" tool in ArcGIS to modify the DEM. The study also identified potential issues of the methodology. First, sinks in the model have to be drained using culverts or storm drain. Second, burning storm network into DEM assumes that runoff can be drained into the network at any point along the course, which does not happen for underground sewer systems since runoff only enters the system through manholes or stormwater intakes.

In addition, stormwater facilities including detention and retention basins need to be considered when delineating watersheds. Detention basins are designed to 
only temporally store water and thus slow down water into the downstream pipes or natural channel. By contrast, retention ponds are designed to store water from precipitation and runoff, which prevents water from flowing downstream. For delineation purposes, no changes need to be made for detention ponds, whereas retention ponds need to be treated as isolated subcatchments (Parece \& Campell, 2015).

\subsection{Importance of Model Calibration}

Our understanding of urban hydraulic and hydrology needs to improve in order to correctly simulate urban drainage systems using computer models. Urban drainage systems have evolved from man-made open channels to more complex drainage systems consist of curbs, gutters, storm intakes, detention and retention basins, and underground storm networks. These hydraulic and hydrological modifications may be very difficult to characterize during modeling accurately. Calibration is often applied to adjust sensitive parameters so that the model represents the watershed more accurately. Calibration is performed to identify model parameters that so that the simulated hydrograph closely matches the observed hydrograph (Zaghloul \& Kiefa, 2001).

\subsection{LID Technologies for Urban Area}

In the past two decades, urban water management has promoted the triple bottom lines which are social, financial, and environmental aspects of potential decisions. For urban stormwater management, LIDs are also known as sustainable urban drainage systems (SUDS) or Water Sensitive Urban Design (WSUD) in different parts of the world, have been used to meet these sustainability goals. LIDs mimic the site's predevelopment hydrology and attempt 
to make the post-development hydrology as close to the pre-development condition as possible. LIDs help conserve water, recharge groundwater, reduce runoff quantity, enhance runoff quality, and protect ecosystems of receiving waters (Flectcher, Andrieu, \& Hamel, 2013). 


\section{Methodology}

The methods and procedures applied to develop a stormwater model for the Cal

Poly campus are illustrated in Figure 3 and will be discussed in this section.

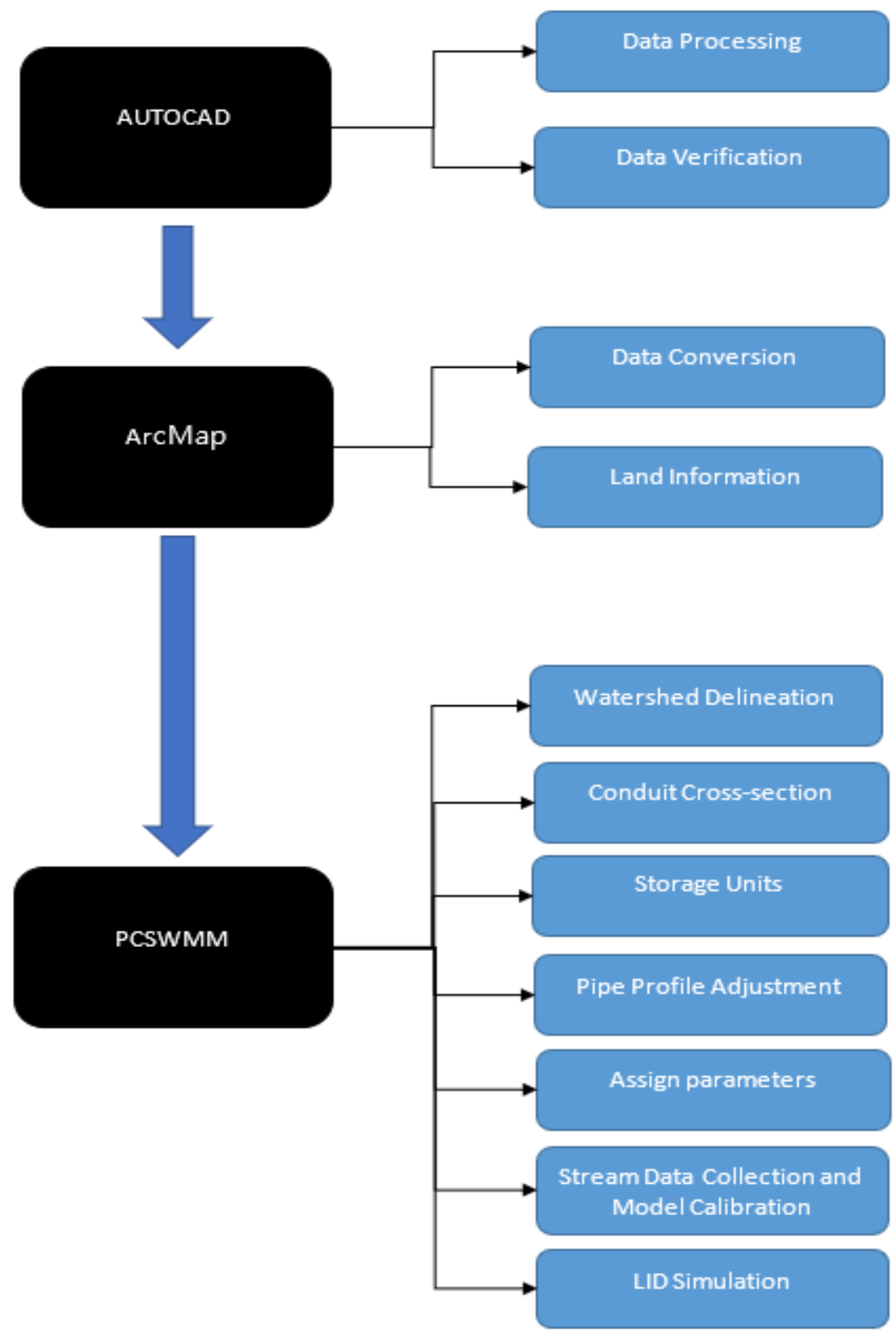

Figure 3 Major Tools Used \& Analysis Performed to Develop the SWMM Model 


\subsection{Data and Material}

Numerous resources were used to develop the stormwater management model.

Data used for developing this model include Cal Poly's storm sewer system, stream network, imperviousness, land cover, digital elevation model (DEM), climate, and streamflow. Most of these data were obtained from open source platforms. The major software used for the study include ArcGIS, AutoCAD, Google Earth, and PCSWMM. Additionally, cloth tape, stadia rod, Hach flow meter, streamflow pole, stoke posts, and clamps were sued to measure streamflow, depth, and velocity for multiple rain events. These flow monitoring instruments were borrowed from Cal Poly's Natural Resources Department.

\subsection{AutoCAD Processing}

AutoCAD was used to manage and modify the utility data that was received from the Cal Poly Environmental Health and Safety unit. The utility data received contains multiple layers of different facility types including potable water pipes, storm sewers, sanitary sewer pipes, electricals, and telecommunication lines.

\subsubsection{Data Processing}

The first step in AutoCAD was to confirm the accuracy of the utility data. After speaking with Mr. Weber, the facility CAD specialist in the Facilities Planning and Capital Projects unit regarding the definition of each layer, only UD_Stenner, UD_Bizzorlara, and UD_General layers were selected for further analysis since only storm pipes were considered in the model. Once the layers were isolated, overland flow paths were drawn manually in AutoCAD by using a topographic map, base map, and Google Earth as a reference to estimate overland flow paths from each outlet to downstream inlet. For the paths between outfall and 
rivers, the paths were created in ArcMap since the river data in the AutoCAD file was outdated whereas the river data on the Cal Poly GIS Server was up to date. Thus, the flow path estimation from outfalls to rivers was performed in ArcMap after the utility data was converted into a GIS compatible format.

As shown in Figure 4, each symbol represents a different type of hydraulic structures in the utility data. The line features in Figure 4 represent drainage lines. The dash line features were deleted since those lines represented pipes that were abandoned. Clean-out points were not considered in the model because clean-out points do not drain runoff into the underground storm drain system. Hydraulic units such as inlets and manholes were drawn as square or octagon symbols in AutoCAD. ArcMap treats those units as closed loop polylines. Therefore, the hydraulic unit symbols were manually replaced by point features before converting the CAD data to ArcMap.

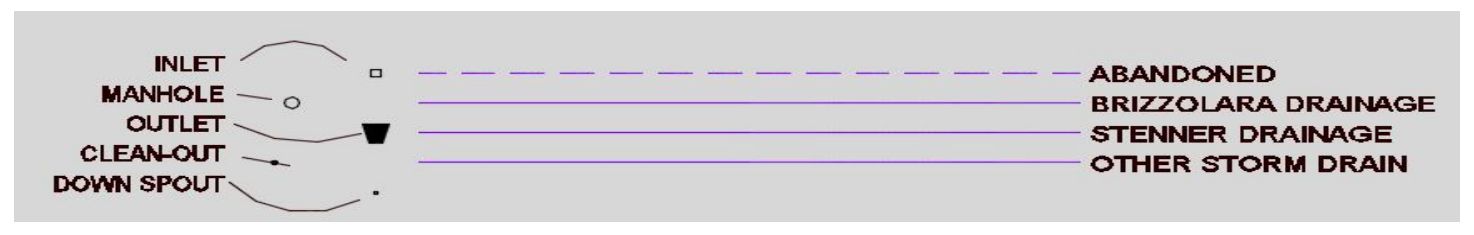

Figure 4 Details of the storm sewer layers obtained in AutoCAD format

\subsubsection{Field Survey}

Field survey is very important to confirm the reliability of the utility data. Given the difficulty to access underground storm drains, manholes and inlets were the only two units investigated during the field survey. Areas around Poly Canyon Village (PCV), Orfalea College of Business building, and Construction Innovations

Center were chosen for the field survey due to time limitation. 
The survey helped clarify few issues regarding the features in the utility data.

First, some pipes were very short, and their orientations were perpendicular to the main pipelines in the utility file (see Figure 5). Those pipes were identified as trench drains during the field survey (See Figure 6). For the modeling purpose, a trench drain was modified as a pipe with inlets at both ends. By doing so, runoff can enter the pipe at both endpoints and convey to the main pipe. Second, downspouts were depicted as pipes without inlets on the utility files. Following the field survey, inlets were added to the downspouts to capture runoff from the buildings and convey it to the storm pipe system. Lastly, the locations of stormpipe outfalls in the utility file were identified for the PCV, Orfalea College of Business building and Construction Innovations Center. Overall, the field survey improved the accuracy of the utility data. Then, the modified AutoCAD file was imported into ArcMap for further processing.

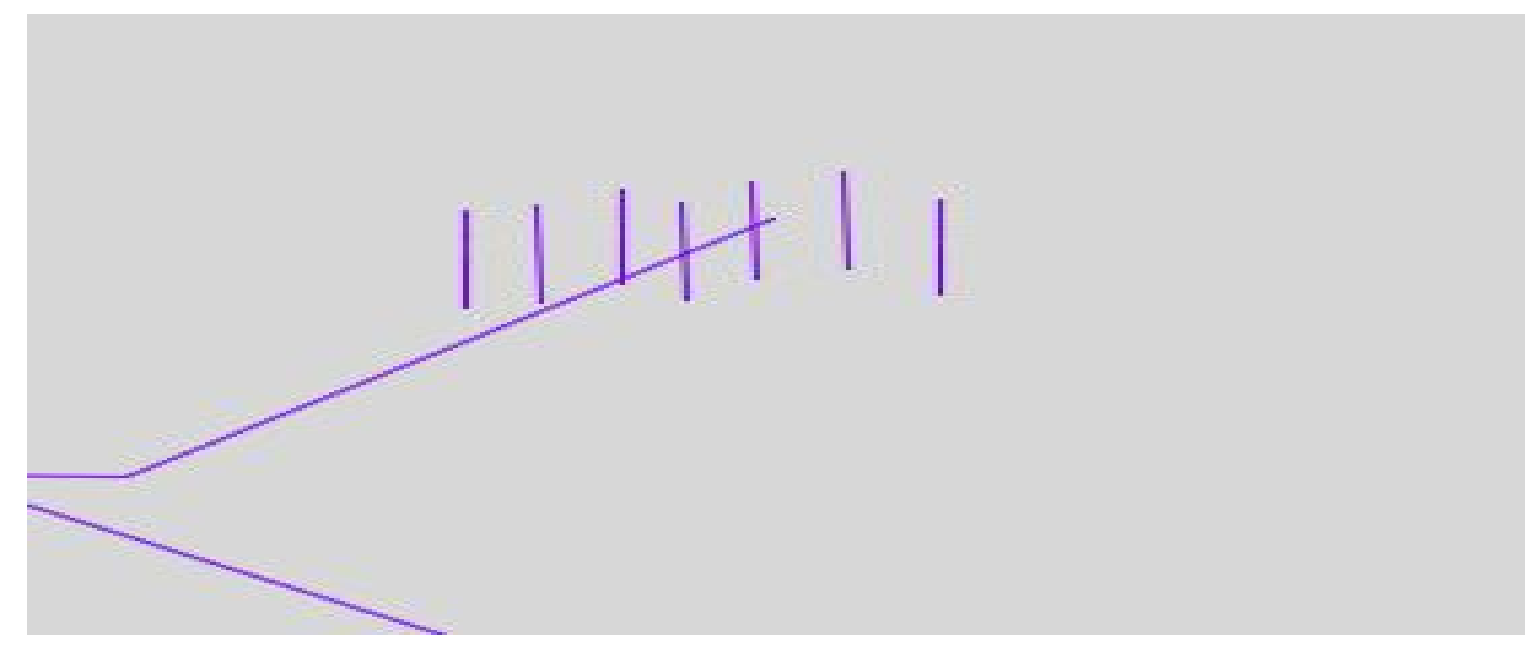

Figure $5 \mathrm{~A}$ trench drain in the utility file 


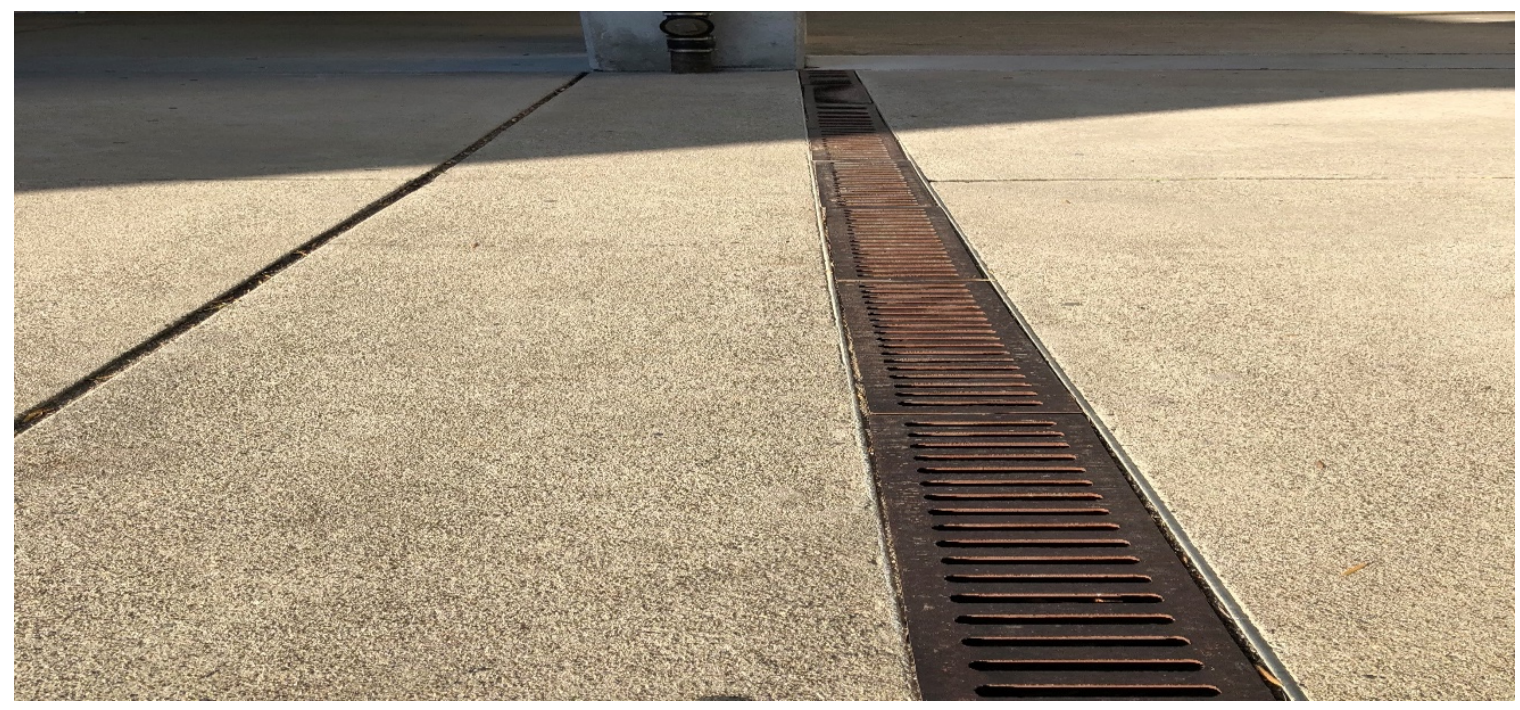

Figure 6 A trench drain on Cal Poly campus

\subsection{ArcMap Processing}

ArcMap from Environmental Systems Research Institute (ESRI) was used to perform a variety of analysis including converting data from AutoCAD to GIS, extracting land information, creating flow paths between outfalls and rivers, and identifying the size of subcatchments outside the one-meter DEM boundary but within the study watershed.

\subsubsection{Data Conversion}

Once the utility file had been corrected and modified, the feature named CAD to GeoDatabase in ArcMap was used to convert the modified data into GIS. The spatial reference of NAD 1983 StatePlane California V FIPS 0405 (US Feet) was used throughout the entire process.

\subsubsection{Land Information Extraction}

ArcMap was used to process the preliminary watershed delineation for analyzing land information including curve number $(\mathrm{CN})$, imperviousness, and slope for 
each subcatchment by utilizing an extension in ArcMap called HEC-GeoHMS. Several steps were performed in HEC-GeoHMS including DEM reconditioning, fill sinks, flow direction, flow accumulation, stream definition, stream segmentation, catchment grid delineation, catchment polygon processing, drainage line processing, and adjoint catchment processing. Detail of these steps is available from HEC-GeoHMS user's manual (U.S. Army Corps of Engineers, Hydrologic Engineering Center, 2009). Next, soil data from ESRI, imperviousness, and land cover grid from United States Geological Survey (USGS) were used to analyze characteristics of each subcatchments. The land cover was reclassified to five general categories including water, forest, grassland, developed and agriculture.

The Curve number method was used to model infiltration from the subcatchments since $\mathrm{CN}$ value is readily available for the study area. To assign $\mathrm{CN}$ for each subcatchment in the map, a $\mathrm{CN}$ reference table was created. Once the table was created, the create $\mathrm{CN}$ grid tool was run to assign $\mathrm{CN}$ to each subcatchment by interpolating the values from the $\mathrm{CN}$ table. By choosing the most downstream location where the two creeks merged outside of the campus boundary as a project point, a subbasin and river layer were created. Another toolset named select HMS processes was ran to extract imperviousness information. After this process was finished, a layer with all the necessary land information and the required data were ready to import to PCSWMM for further analysis. 


\subsubsection{Subcatchment Outside of the One-meter DEM Boundary}

Since the one-meter DEM did not cover the entire campus boundary, a fivemeter resolution DEM that covers the entire campus boundary was used to estimate the size of subcatchments that were outside the one-meter DEM coverage but were within the campus boundary. The subcatchments and their characteristics including size, $\mathrm{CN}$, imperviousness, and slope were assigned to PCSWMM manually.

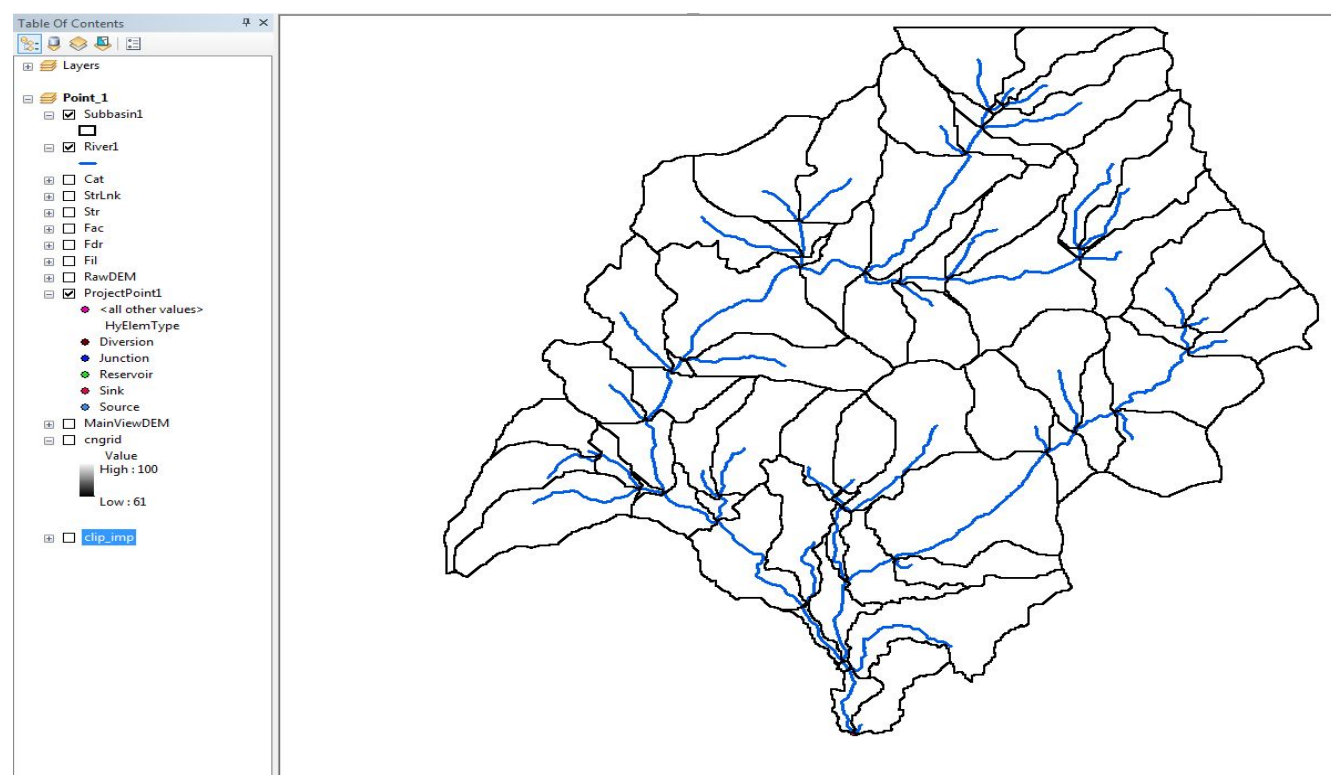

Figure 7 The watershed delineation result of the City of San Luis Obispo 


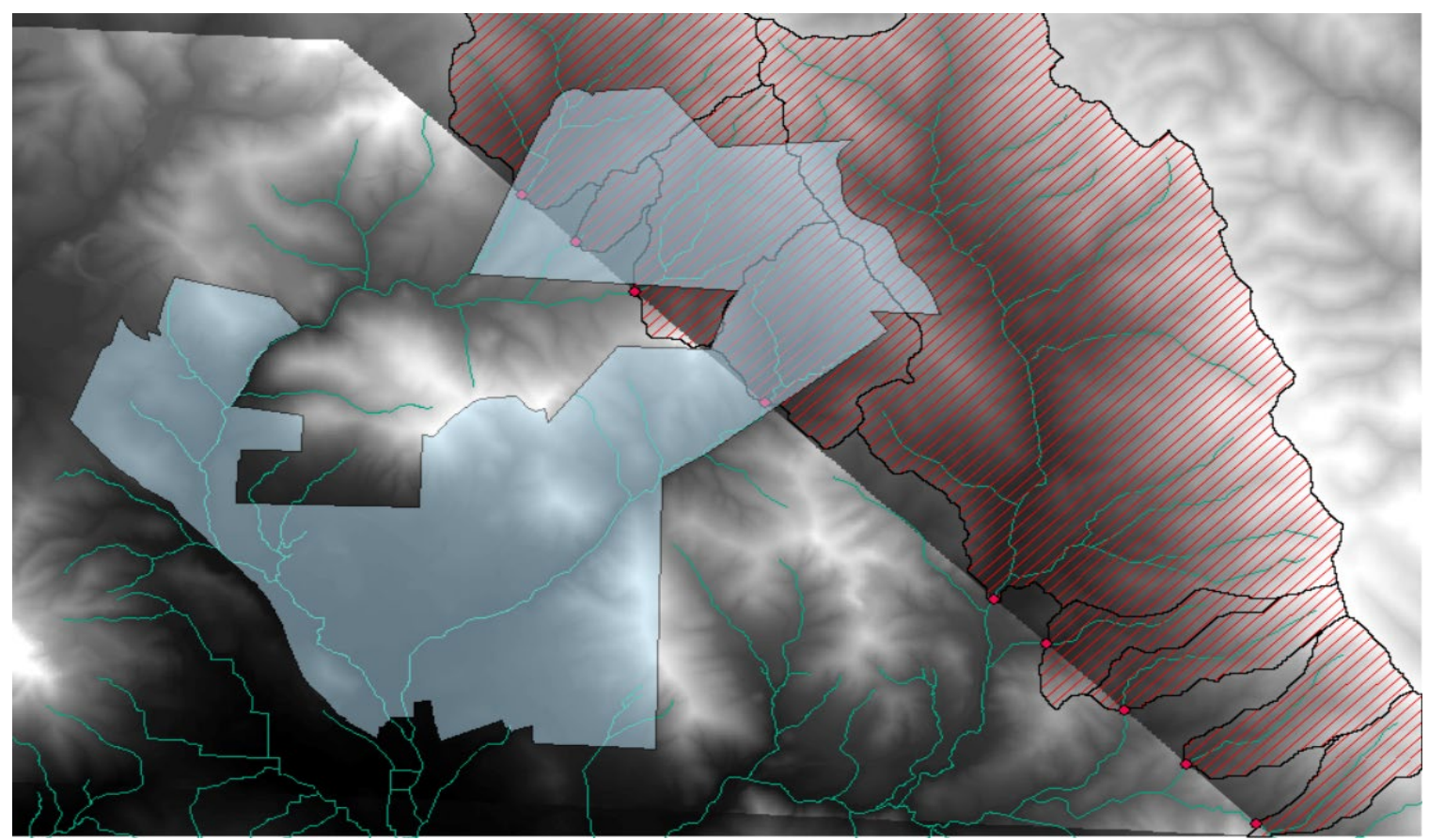

Figure 8 The delineation result of subcatchments that were outside of the one-meter DEM boundary (Blue Polygon). The straight line crossed the campus boundary indicated the edge between one-meter and five-meter $D E M$, and the hatched polygons with red lines indicated the subcatchments outside of the one-meter DEM border

\subsection{PCSWMM Processing}

PCSWMM uses the SWMM 5 engine to simulate the hydrological impact of the environment, and the software is compatible with GIS and CAD programs such as ArcGIS to import/export inputs and outputs between different programs. The procedures followed to develop the PCSWMM model for the study area will be described in this section.

\subsubsection{Watershed Delineation Tool}

The watershed delineation tool (WDT) in PCSWMM was used to accomplish the watershed delineation process to create an arborescent SWMM network of subcatchments. Compared with the existing watershed delineation program, WDT in PCSWMM provides more functionality including preserving hydraulic 
entities, and the program automatically runs through most of the steps to build up a model with the necessary conduits and junctions.

One-meter resolution DEM of the City of San Luis Obispo was used as the DEM layer, a feature class with the storm-pipe network and streams merged was assigned as a burn-in layer in PCSWMM, and a layer with all the existing hydraulic units including inlets and manholes was assigned as the delineation points layer. Target discretization is a key parameter to decide how detailed the watershed delineation will be. In this study, seven acres was used as target discretization so that too small subcatchments were not created. Before running WDT, three pour points (ArcGIS uses this term to represent the location where concentrated water exits a particular catchment) were added to the downstream of the watershed where the most downstream overland flow paths intersect with the creeks. The minimum size of the subcatchments outside the main campus was set to 10 acres whereas the subcatchments on campus core could be as small as 0.1 acres. At the end, the study area was divided into 636 subcatchments. 


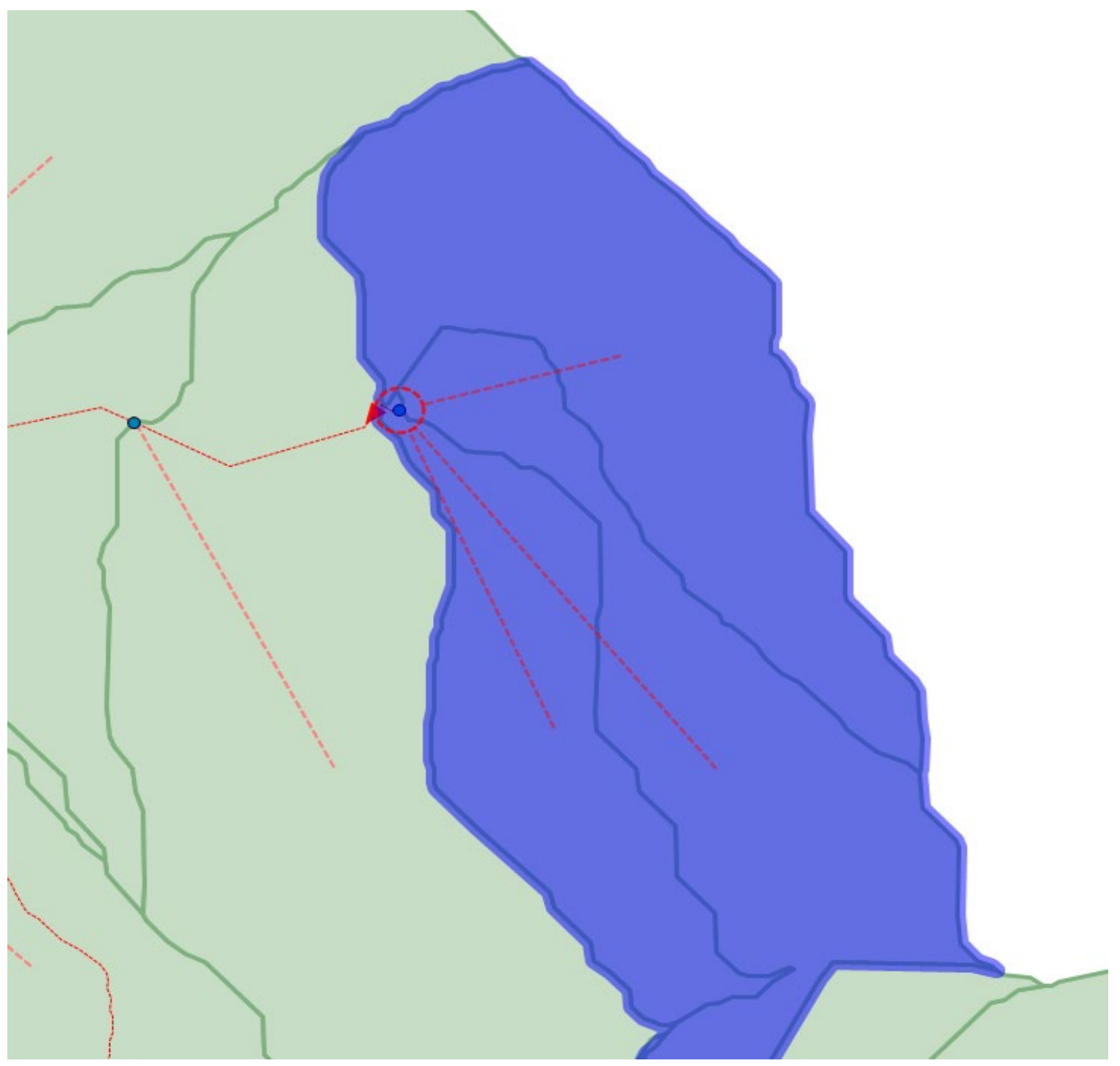

Figure 9 Multiple subcatchments were merged by using the join command if they shared the same outlet. The red dash-lines indicated the outlet junctions of each subcatchment

Network connectivity was checked to ensure connectivity between junctions and links, and between subcatchments and their respective outlets. The tool named select orphan was used to identify the non-connected entities. The nonconnected features were corrected using the stream burn-in layer as a guide to identify flow paths and the location of the junctions and conduits. Once the extraneous subcatchment were deleted and the subcatchment that did not match 
the size requirement were merged, a tool called area weighting was performed to determine $\mathrm{CN}$ and imperviousness for each subcatchment. For the area weighting tool, the land information polygon layer (delineation) created in ArcMap was used as a background layer, and the subcatchment layer was used as the target layer. The area weighting tool uses Equation 1 to calculate $\mathrm{CN}$ and imperviousness for each subcatchment.

$$
W A M=\frac{\sum_{i=1}^{n}\left(x_{i} \times w_{i}\right)}{\sum_{i=1}^{n} w_{i}}
$$

Where:

$$
\begin{aligned}
\text { WAM } & =\text { the weighted arithmetic mean for the area of interest } \\
x_{i} & =\text { the ith value } \\
W_{i} & =\text { the weight for the ith value } \\
n & =\text { the number of values to be weighted }
\end{aligned}
$$

Equation 1

\subsubsection{Assigning Conduit Information}

\subsubsection{Pipe Diameter}

Pipe diameters were inferred for majority of the storm drains from the utility data and were manually assigned to the pipes in PCSWMM. Most of the pipes missing size information were those directly connected to outfalls and those directly draining to the creek but not connected to the storm drain network. In addition, the storm sewer network constructed under the Cerro Vista Circle 
student apartment did not have pipe size information. The minimum diameter of 8-inch was used for the pipes guided by data for storm drain network under Poly Canyon Village.

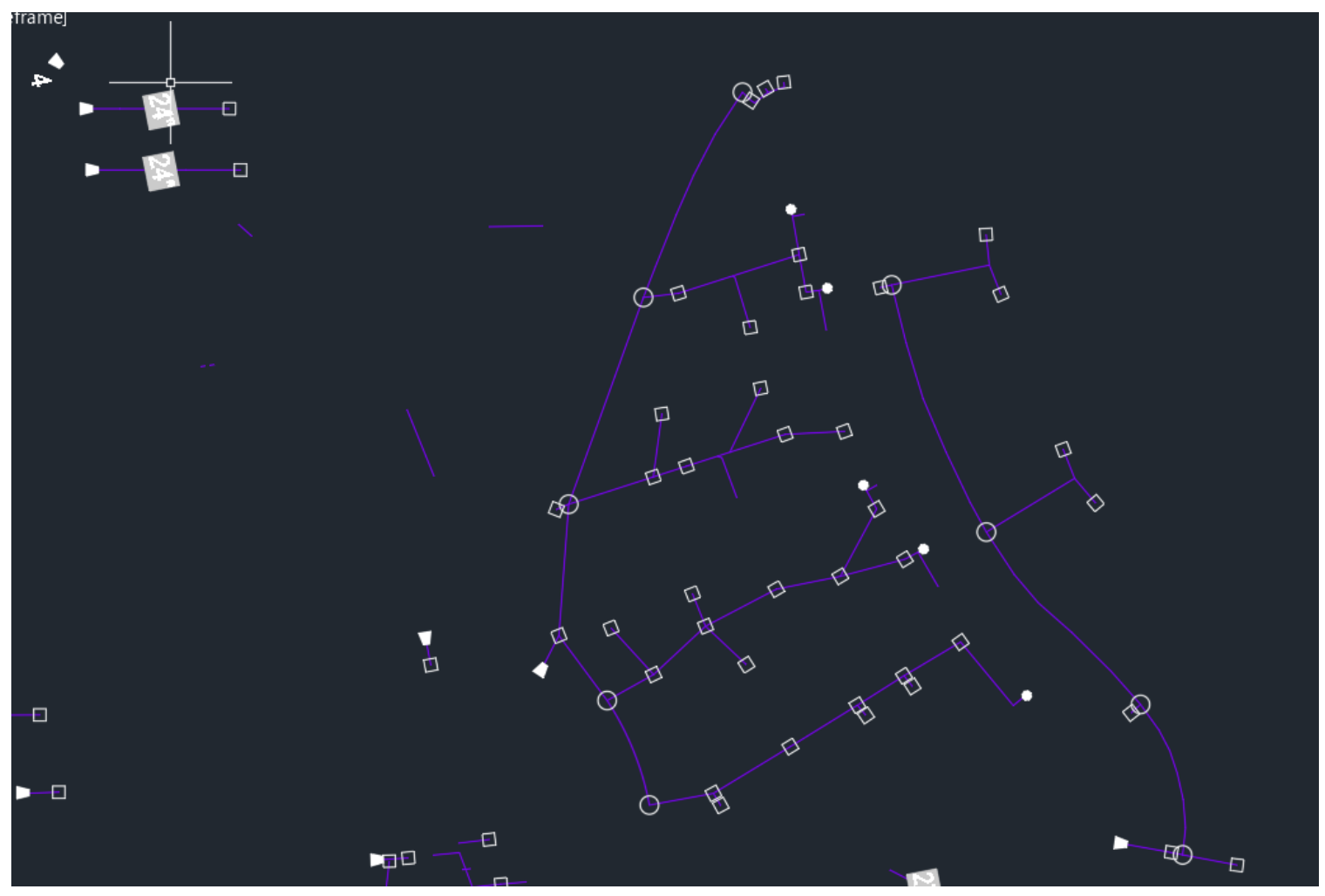

Figure 10 The sewer network located near Cerro Vista Circle student apartment did not have pipe diameter information in the utility file

\subsubsection{Overland Flow Cross-Sections and Creeks}

Overland flow paths and rivers typically have irregular shapes. The transect tool in PCSWMM was used to create cross-sections for the irregular channels.

Transect Lines were automatically created for all overland flow and creek paths in the study areas using a DEM layer and the flow path layer created from the previous delineation process. The created transect lines were then examined and modified (if needed). For example, Figure 11 shows a transect line created 
for conduit CON123002. Unreasonable transects like that were modified either by widening/shortening the transect line to accommodate the entire width of the waterway and generate more realistic cross-section as shown in Figure 12.

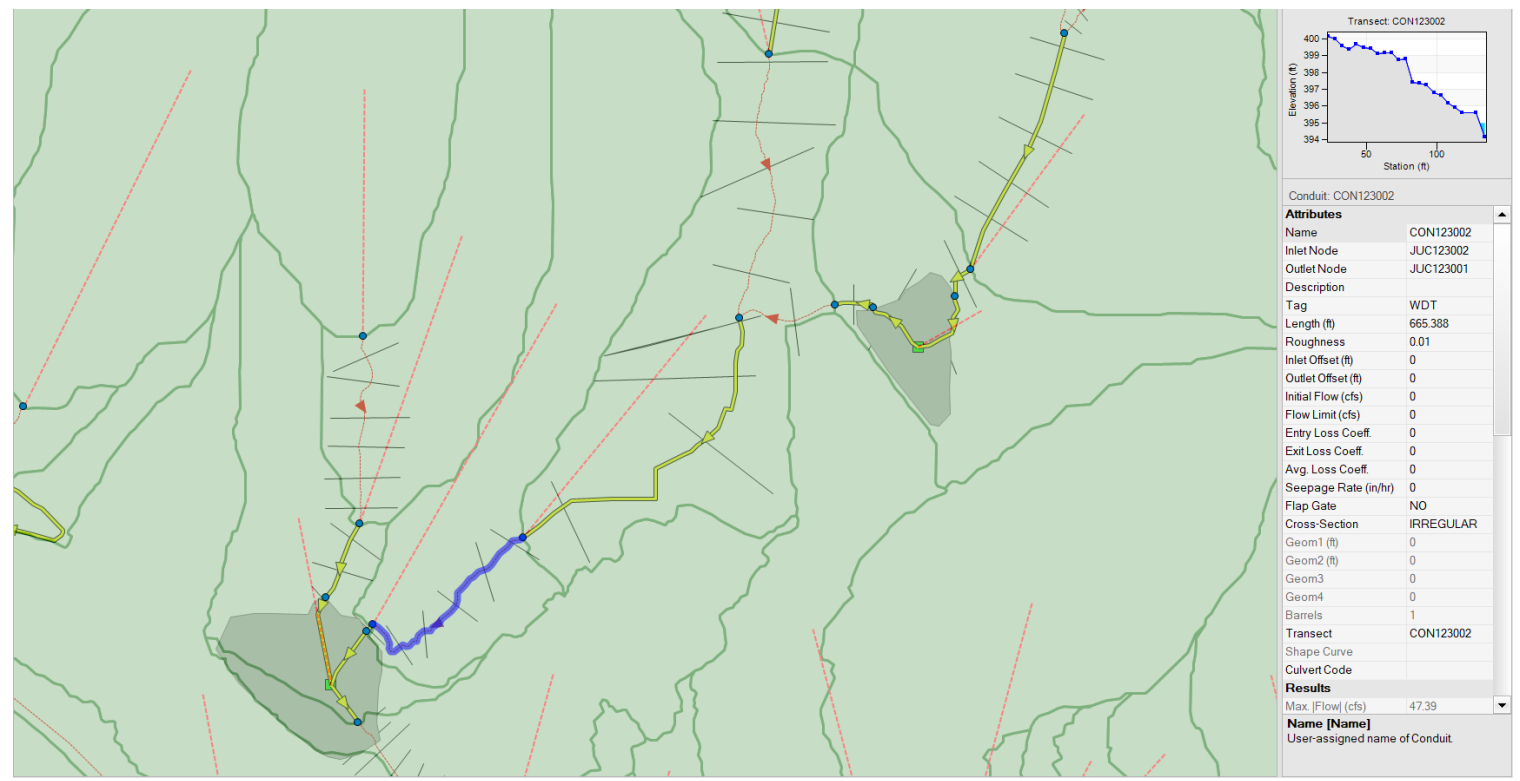

Figure 11 Unrealistic cross-section created by PCSWMM for one of the conduits

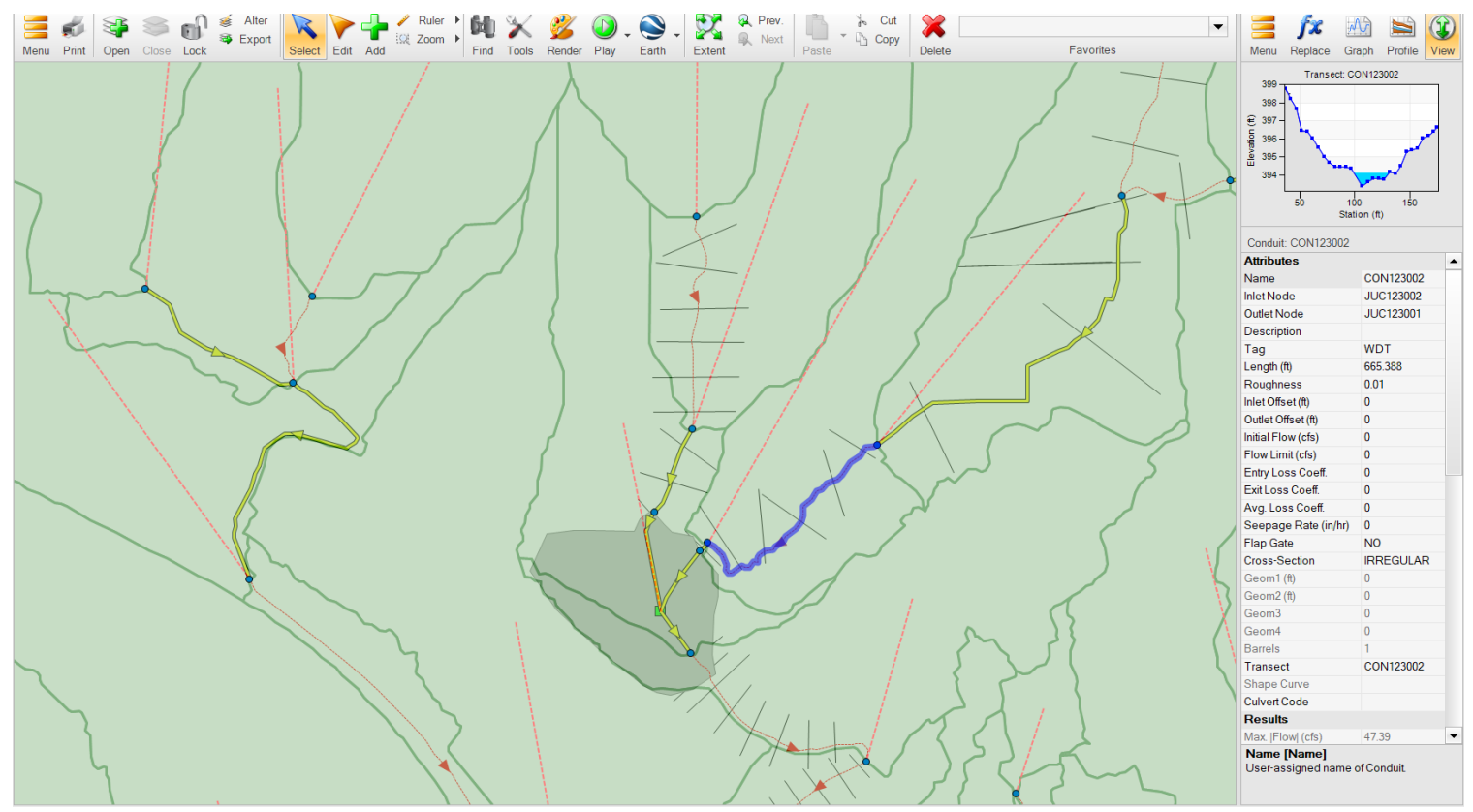

Figure 12 A corrected transect for the conduit 
After all, transects were checked and modified (if needed), the transect objects tool was used to assign one cross-section per conduit by averaging all transects for the conduit or by splitting the conduit into multiple conduits that each conduit had a unique cross-section. The averaging option was used in this study for simplicity. The splitting option was used for conduits that PCSWMM was not able to do the averaging option.

\subsubsection{Storage Units}

Storage units play an important role in preventing flooding and storing water for multi-purpose usage. A storage unit can allow rainwater to store in the unit until water depth reaches a certain depth, and water will either flow into pipes connected to the unit to downstream pipes or form overland flow after the design depth is reached. By contrast, a subcatchment is only able to catch and conduct rainwater to a downstream outlet or a junction. During a rain event in a fully developed area, most of the runoff flow toward downstream subcatchments and only a small portion of the runoff can be infiltrated by the subcatchments.

Locations of the storage units on campus were identified using Google Earth and the topographic map. Four reservoirs named Drumm, Shepards, Indonesian and Nelson reservoirs are located in the study area. Drumm reservoir is the only reservoir located within the campus core. Storage area curves that represent storage depth vs. surface area at each depth for were extracted from topography maps using PCSWMM. Figure 13 shows an example storage curve. 


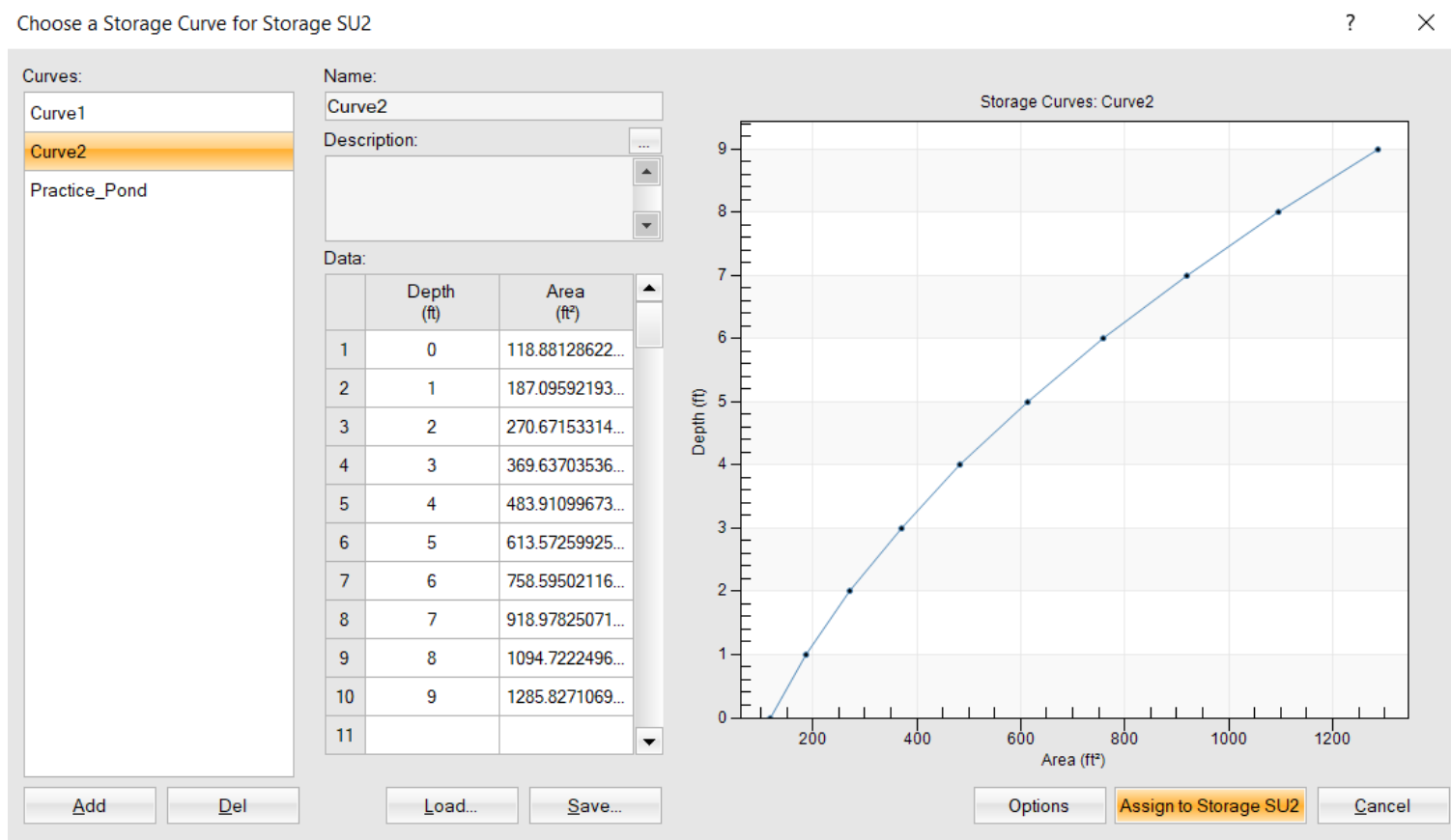

Figure 13 A storage curve for a storage unit

Extracting storage curve from contour map was not effective for reservoirs. The most inner contour line at a reservoir represented the current ground surface level rather than the bottom of the reservoirs. If the storage-area curve extraction method previously described was applied for the reservoirs, the bottom of the reservoirs would be simulated as the current ground surface level, thus underestimating the reservoir capacity. Fortunately, the surface area and total capacity data shown in Table 1 were obtained for the reservoirs on Cal Poly Camps from the Water Quality Management Plan for Cal Poly Land in San Luis Obispo Creek and Chorro Creek Watershed report. Information from Table 1 and the topography maps were used to extract storage area curves assuming all four reservoirs have vertical sides. 
Table 1 The information about the reservoir systems at Cal Poly

\begin{tabular}{|l|c|c|c|c|c|}
\hline $\begin{array}{c}\text { Reservoir System } \\
\text { San Luis Obispo Creek } \\
\text { Watershed }\end{array}$ & $\begin{array}{c}\text { Date of } \\
\text { Construction }\end{array}$ & $\begin{array}{c}\text { Surface Area } \\
\mathbf{( f t}^{{ }^{2} \text { ) }}\end{array}$ & $\begin{array}{c}\text { Surface } \\
\text { Area (ac) }\end{array}$ & $\begin{array}{c}\text { Capacity } \\
\text { (ac-ft) }\end{array}$ & $\begin{array}{c}\text { Vegetation } \\
\text { Audit }\end{array}$ \\
\hline Middlecamp & 1965 & 59677 & 1.4 & 11.0 & Yes \\
\hline Indonesian & $1956 / 57$ & 111949 & 2.6 & 20.6 & Yes \\
\hline Ketcham Frog Pond & 1950 & 25000 & 0.6 & $1 / 8$ shallow & Yes \\
\hline Nelson & 1950 & 182952 & 4.2 & 33.6 & Yes \\
\hline Drumm & $1908-1913$ & 67200 & 1.5 & 12.0 & Yes \\
\hline Shepard & 1947 & 130000 & 3.0 & 34.0 & Yes \\
\hline Smith & 1949 & 32670 & 0.8 & 6.00 & Yes \\
\hline
\end{tabular}

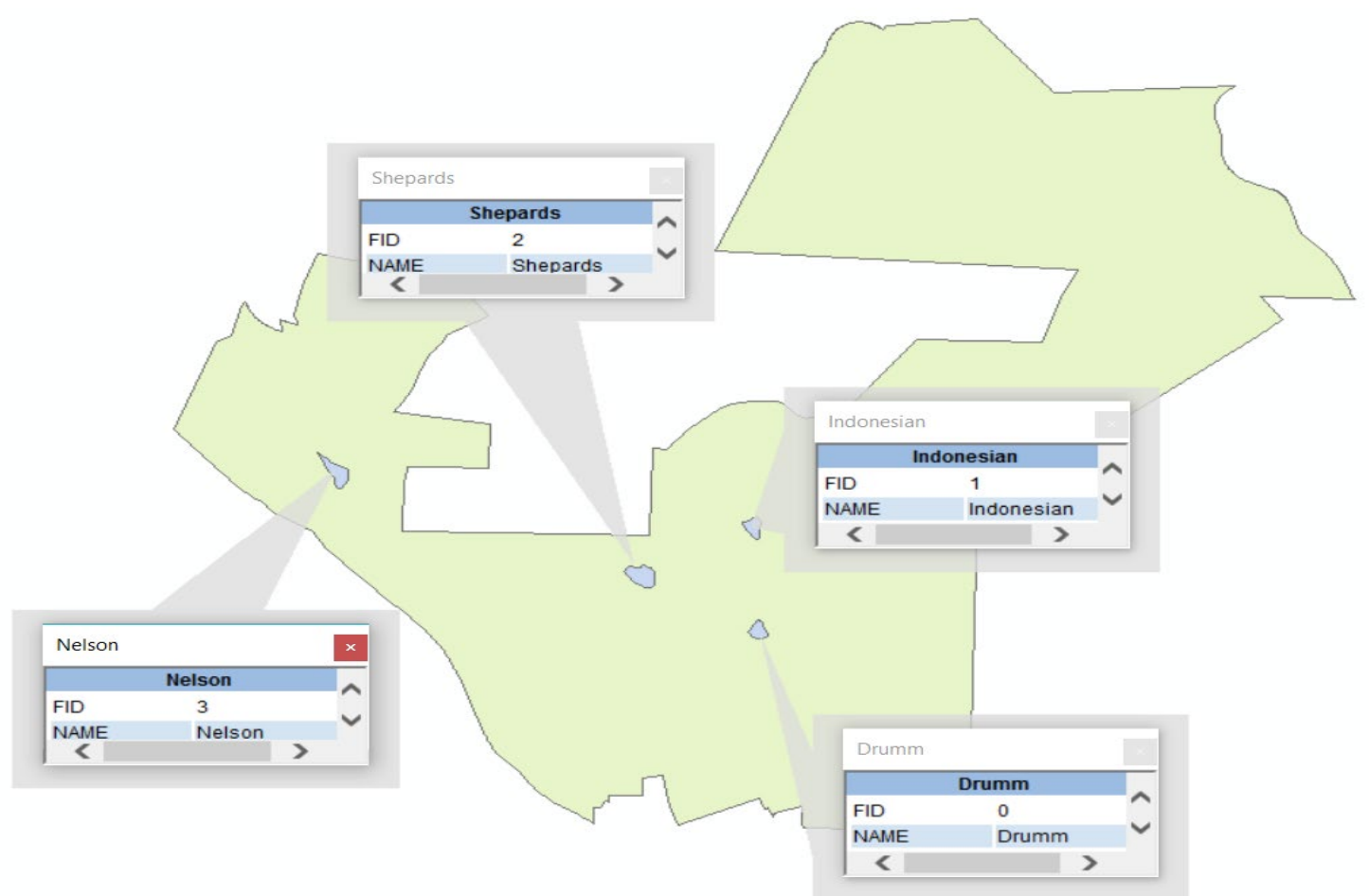

Figure 14 The location of reservoirs within the San Luis Obispo Creek watershed

\subsubsection{Pipe Profile Adjustment}

Rim elevation of manholes and inlets (i.e., the elevation at the top of a manhole) and invert elevations of pipes were not available in the utility file. Rim elevations were inferred from the 5-meter DEM layer assuming rim elevations are same as ground elevations at the locations of manholes and inlets. After rim elevation was extracted, depth of manhole/inlet was subtracted from the rim elevation to 
determine the invert elevation. Four feet was used as the depth of manhole/inlet. If the invert elevations calculated produce positive slope, and manhole/inlet depth is bigger than the pipe that is connected to the manhole/inlet, then no further modifications were implemented. If the slope of the conduit is negative, then depths of the junctions connected to the conduit were modified to ensure positive slope.
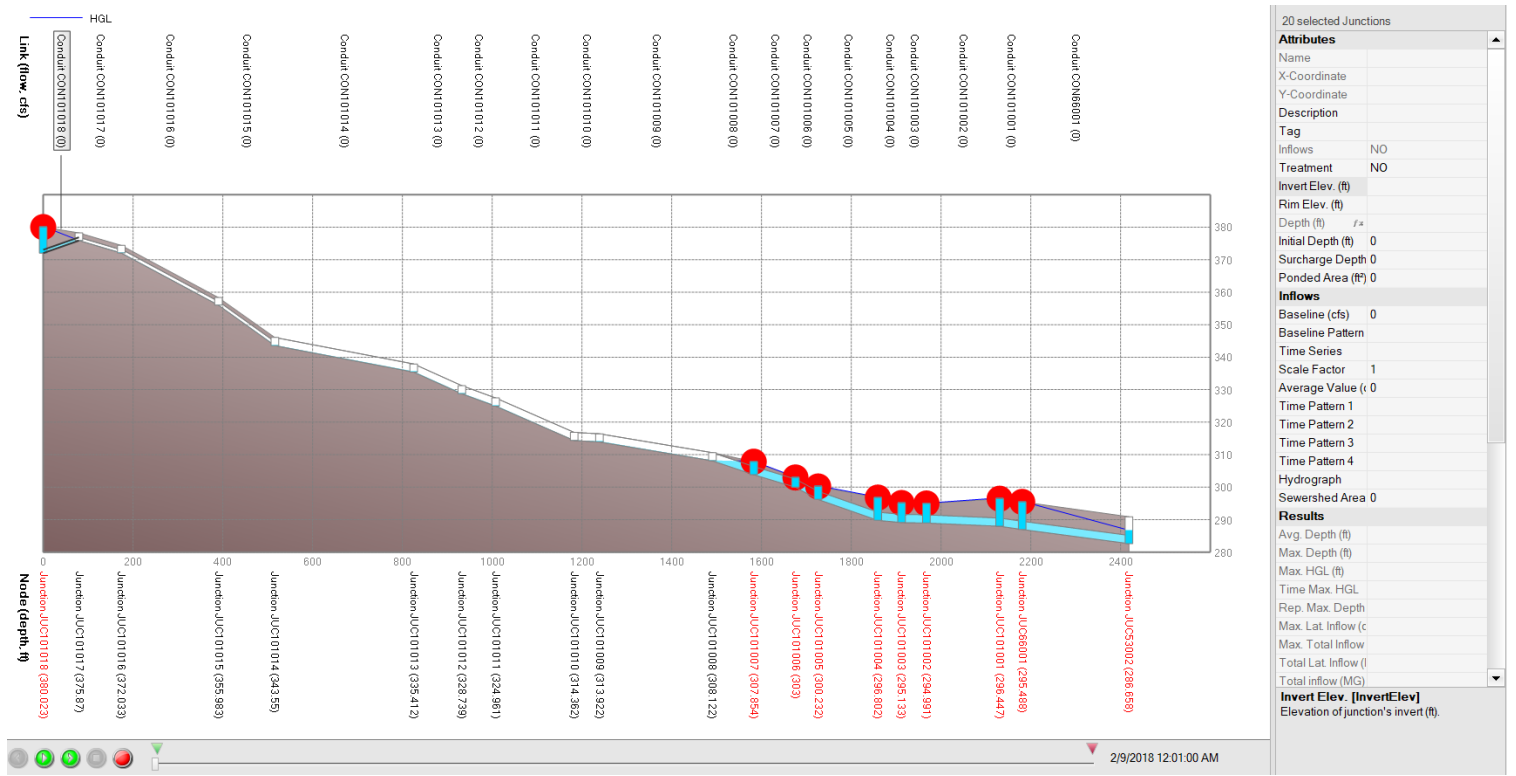

Figure 15 The profile of a conduitjunction path

\subsubsection{Streamflow Monitoring}

There is no stream gauge on both Stenner and Brizziolara creeks reaches on Cal Poly campus. Model calibration requires good quantity and quality streamflow data so that the data can be compared to model predictions at the observation location. I measured streamflow during three rain events in March 2018 to help with model calibration. The ideal location to measure the data at the confluence of Brizzolara creek and Stenner creek as the data represents hydrologic 
characteristics of the entire study area. However, the confluence point has limited access and posed safety risks, especially during a rain event.

Therefore, another location where Brizzolara creek flows adjacent to the $\mathrm{H}-12$ parking lots was chosen as the measurement location. Measurements were taken at two different locations on March 2nd, March 16th, and March 21st, 2018. Creek cross-sections at the measurement locations were divided into 10 or 20 sections depending on width of the cross-section. A 100-ft long cloth tape was stretched across the channel width to identify the location of each station. A Stadia rod was used to measure the depth of water at each station across the channel cross-section. A streamflow pole and Hach flow meter were operated to measure flow velocity which was measured at 0.6 times the depth of water from river bed at the mid-point of each station. After recording data including time, location, velocity, station location and depth, discharge was calculated using a spreadsheet. Equation 2 was used to calculate discharge. Guidelines to measure streamflow data are available from the United States Department of Agriculture (USDA) (Harrelson, Rawlins, \& Potyondy, 1994).

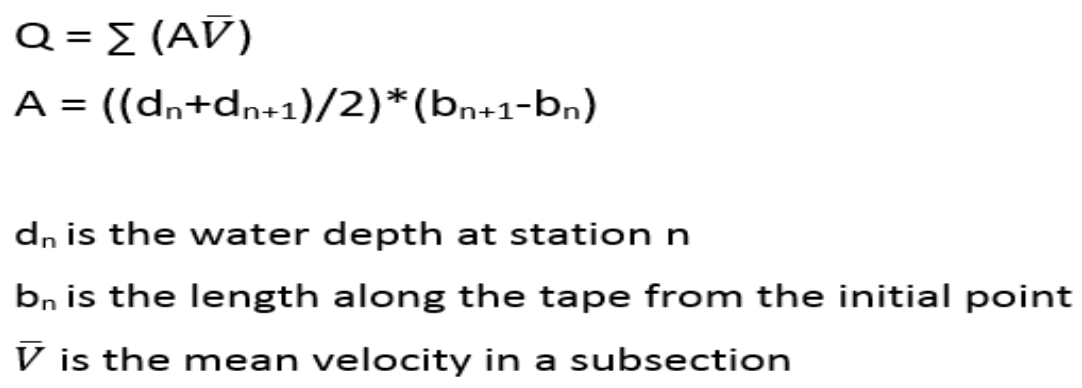




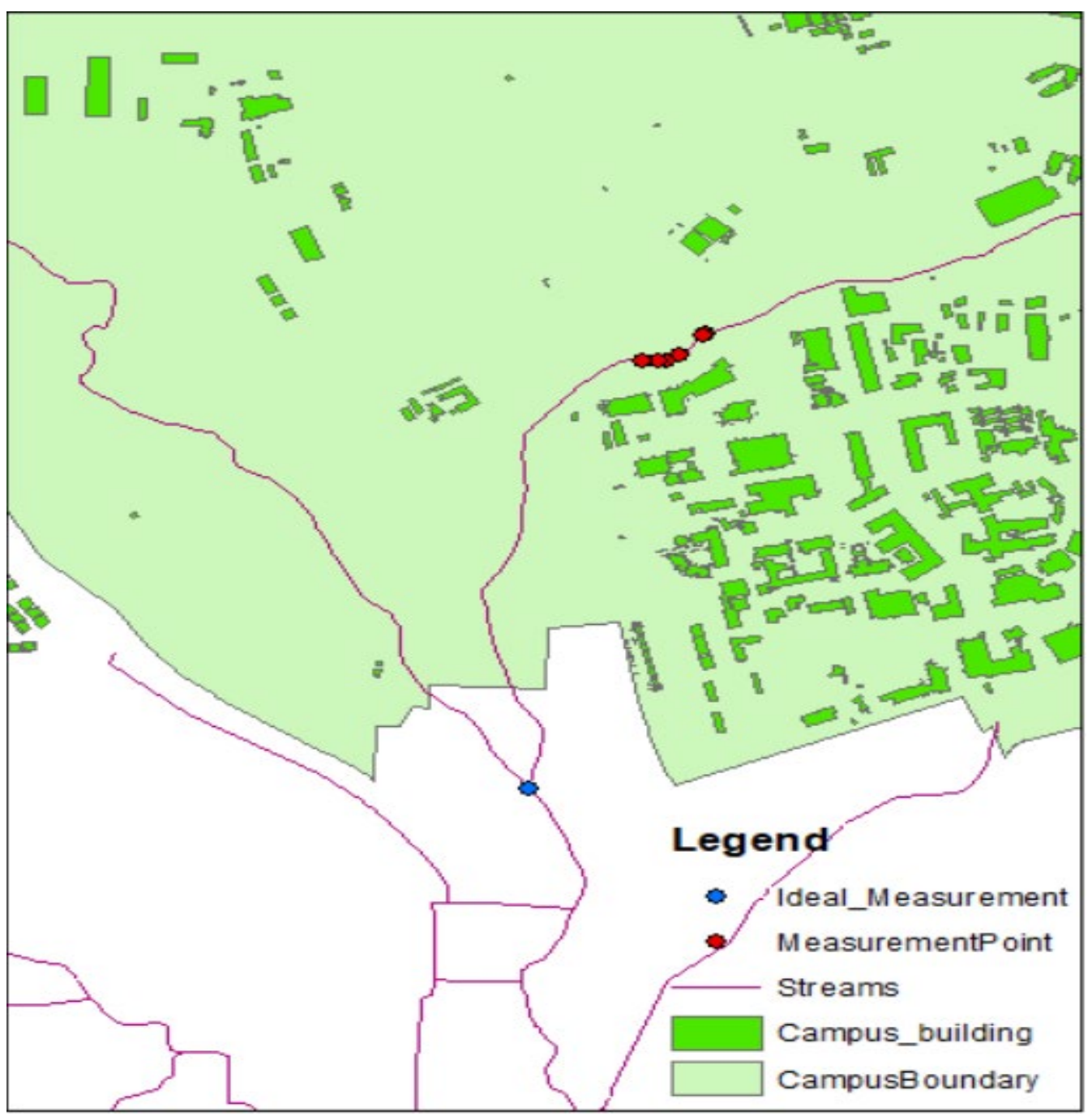

Figure 16 Streamflow monitoring Locations 


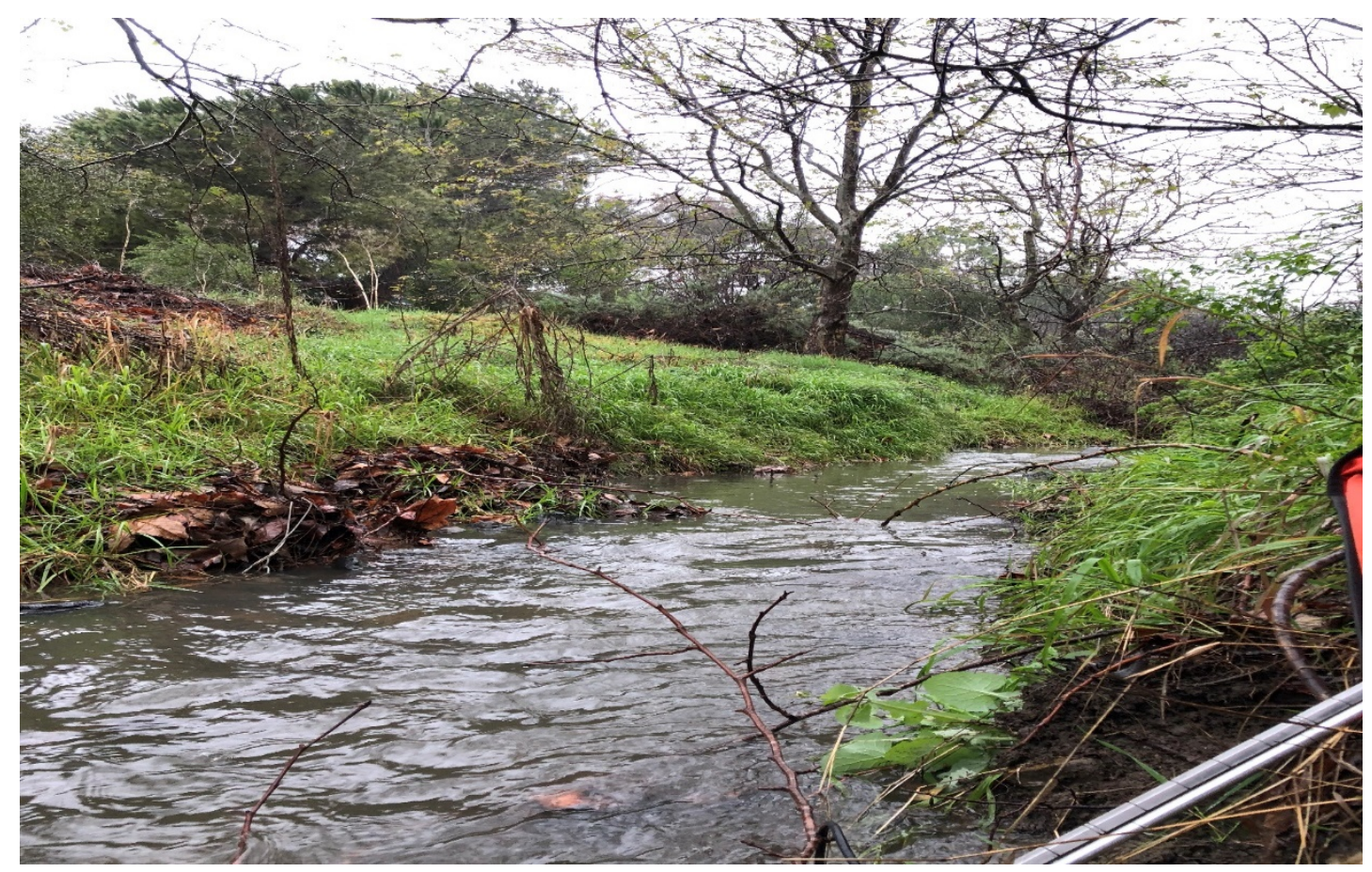

Figure 17 One of the monitoring sites at Brizzolara creek during the rain event on March 16, 2018

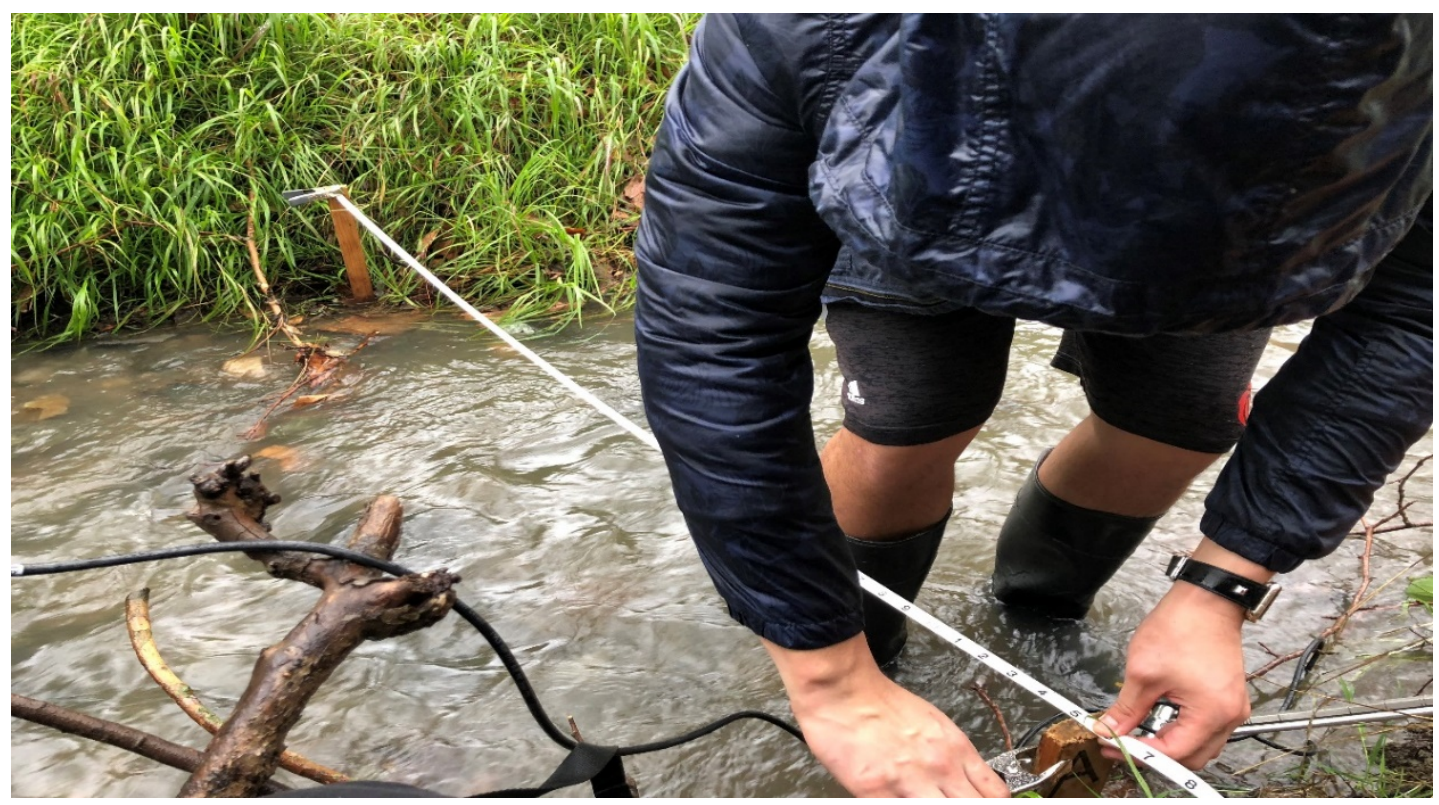

Figure 18 A 100 feet cloth tape stretched across the channel during one of the monitoring efforts 


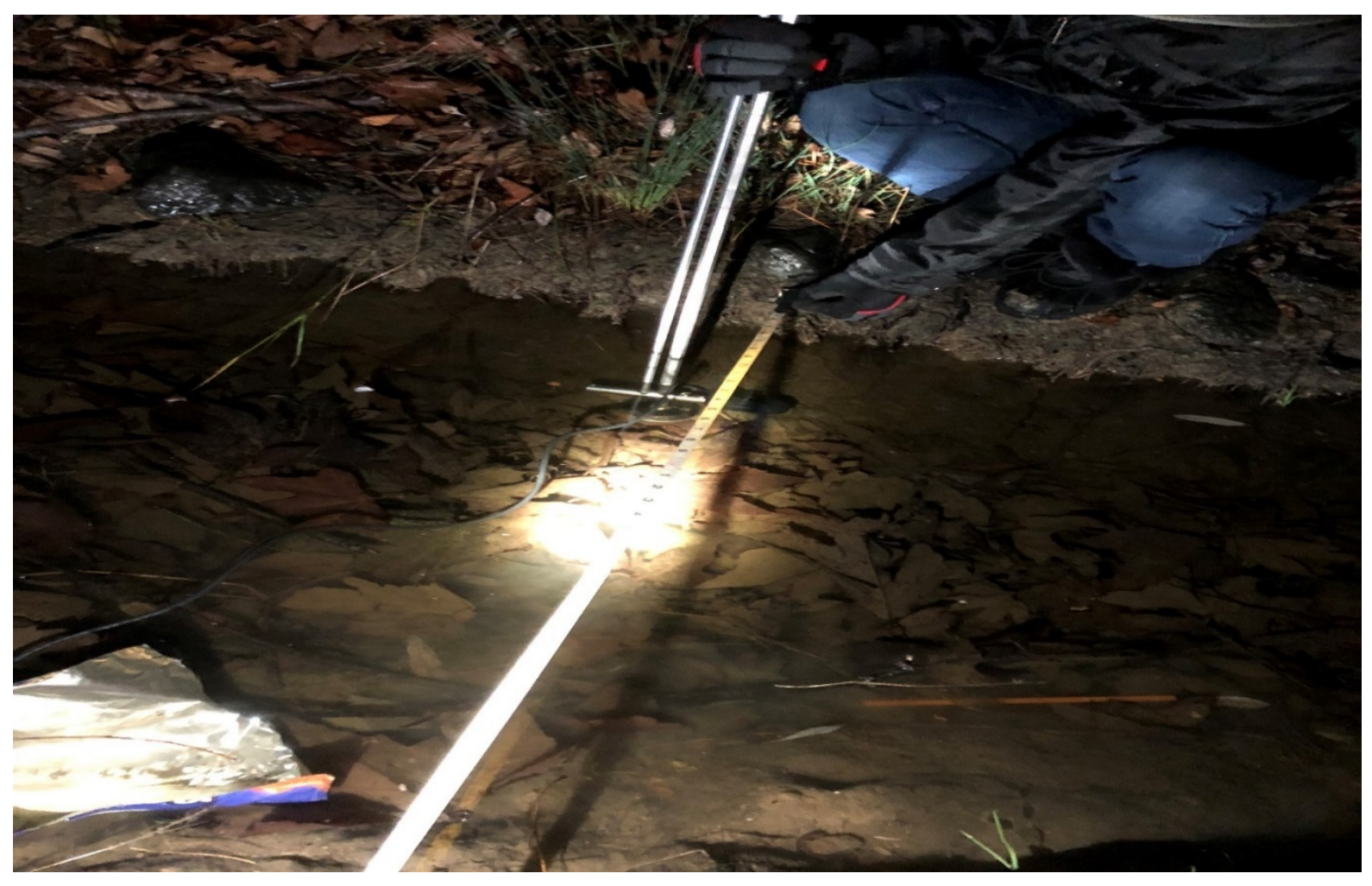

Figure 19 A Hack flow meter was used to measure the current in the river

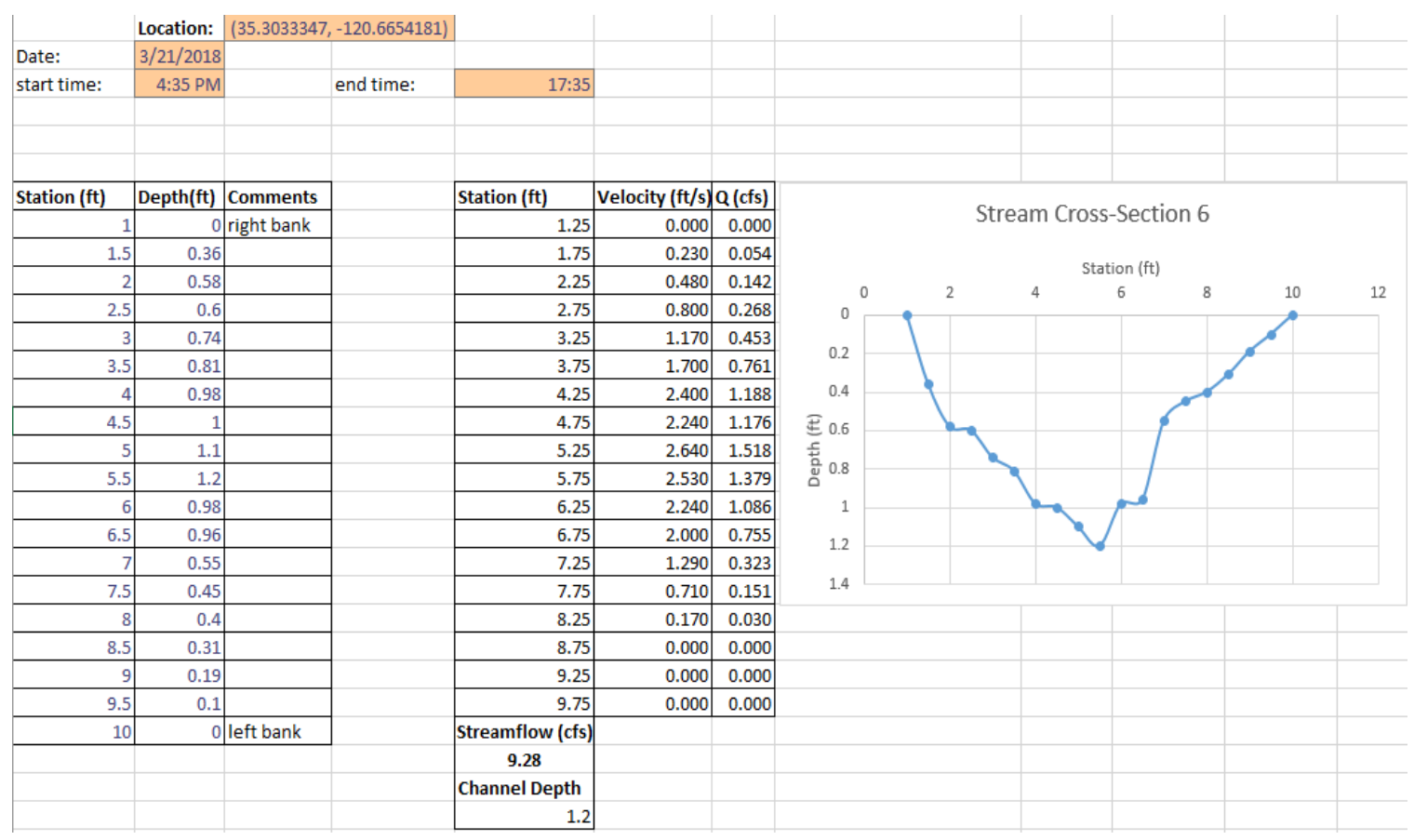

Figure 20 The Excel spreadsheet with the observed data on March 21 


\subsubsection{Subcatchment and Conduit Parameters}

In addition to the subcatchment parameters previously described (e.g., area, CN, slope), SWMM requires subcatchment parameters including the percentage of impervious area with no depression, Manning's $n$ values for the impervious and pervious areas, depth of depression storage for the impervious and pervious areas.

\subsubsection{Manning's N Values for Impervious and Pervious Areas}

Manning's $\mathrm{n}$ values were determined based on land uses in each subcatchments. Most of the impervious area in this model represent either roadways, parking lots or buildings. Buildings were assigned $\mathrm{n}$ value for bricks with cement mortar, and $\mathrm{n}$ value for smooth asphalt was used roadways and parking lots. The View in Google Earth tool in PCSWMM was used to identify the distribution of impervious surfaces by overlaying the subcatchment layer on Google Earth image. For pervious areas, $\mathrm{n}$ values for short, prarie grass were used. Table 2 shows Manning's n values used for this study. 
Table 2 Manning's $n$ value for different land use types (McCuen, $R$. et al., 1996)

\begin{tabular}{|c|c|}
\hline Surface & Manning's n \\
\hline Smooth asphalt & 0.011 \\
\hline Smooth concrete & 0.012 \\
\hline $\begin{array}{l}\text { Ordinary concrete } \\
\text { lining }\end{array}$ & 0.013 \\
\hline Good wood & 0.014 \\
\hline $\begin{array}{l}\text { Brick with cement } \\
\text { mortar }\end{array}$ & 0.014 \\
\hline Vitrified clay & 0.015 \\
\hline Cast iron & 0.015 \\
\hline $\begin{array}{l}\text { Corrugated metal } \\
\text { pipes }\end{array}$ & 0.024 \\
\hline $\begin{array}{l}\text { Cement rubble } \\
\text { surface }\end{array}$ & 0.024 \\
\hline $\begin{array}{l}\text { Fallow soils (no } \\
\text { residue) }\end{array}$ & 0.05 \\
\hline \multicolumn{2}{|l|}{ Cultivated soils } \\
\hline $\begin{array}{l}\text { Residue cover }< \\
20 \%\end{array}$ & 0.06 \\
\hline $\begin{array}{l}\text { Residue cover }> \\
20 \%\end{array}$ & 0.17 \\
\hline Range (natural) & 0.13 \\
\hline \multicolumn{2}{|l|}{ Grass } \\
\hline Short, prarie & 0.15 \\
\hline Dense & 0.24 \\
\hline Bermuda grass & 0.41 \\
\hline \multicolumn{2}{|l|}{ Woods } \\
\hline Light underbrush & 0.4 \\
\hline Dense underbrush & 0.8 \\
\hline
\end{tabular}

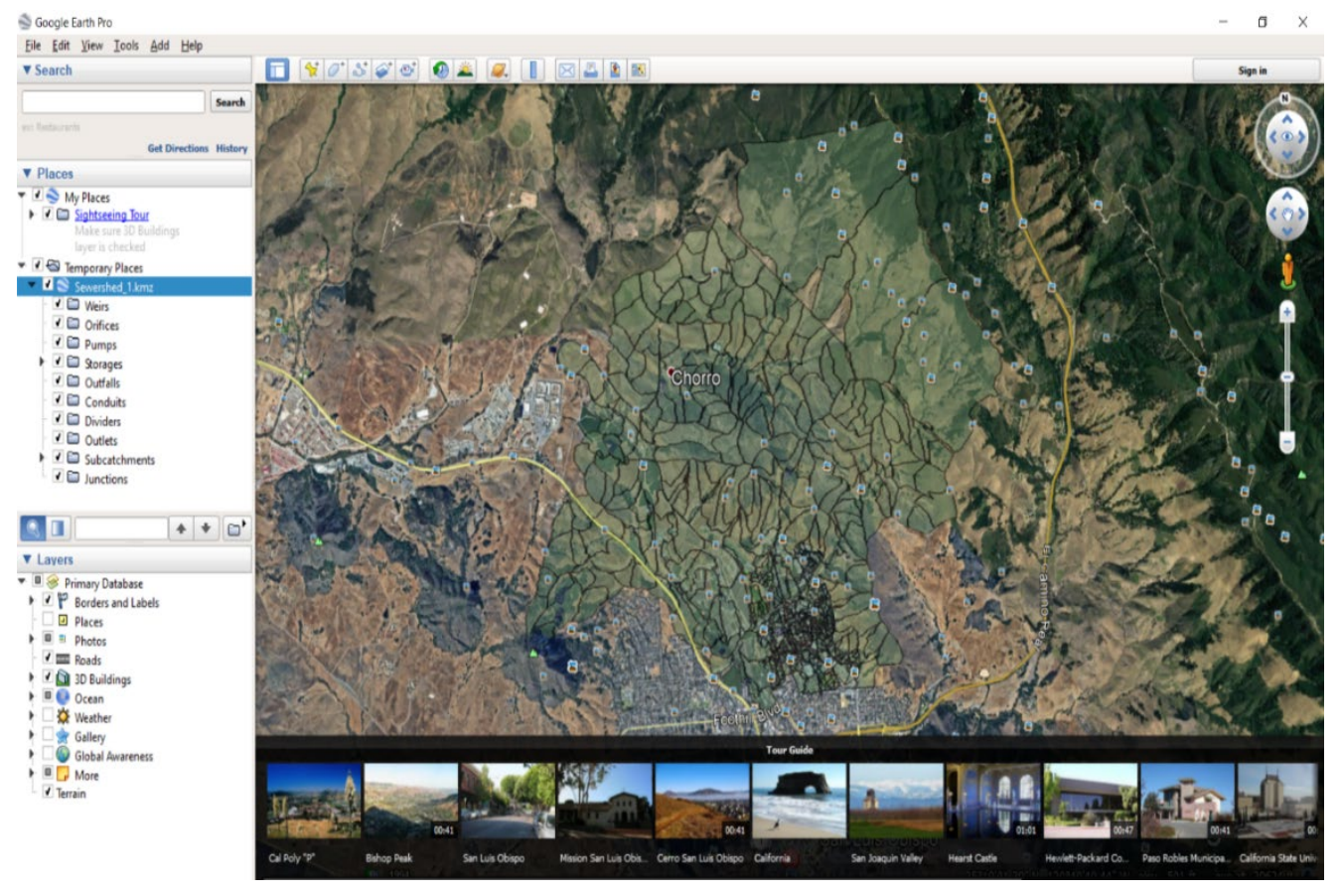

Figure 21 Google Earth was used to identify the distribution of various land uses within the campus boundary. The green polygons are subcatchments 


\subsubsection{Manning's $\mathrm{n}$ values for Conduits}

Manning's $\mathrm{n}$ values play a significant role in determining the characteristics of water flowing in conduits. The $\mathrm{n}$ values listed in Table 3 were taken from the PCSWMM Support website and were used for this study. For open channels such as rivers, average $\mathrm{n}$ value for a fairly regular section of natural channels was used. According to an article that describes storm drain improvements for the City of San Luis Obispo (City of San Luis Obispo), the majority of the city's storm sewer pipes that were installed during the 1960s and 1970s were corrugated metal pipes (CMP). For new Pipes and failing storm sewers, the city is using plastic pipes including polyvinyl chloride (PVC) and high-density polyethylene (HDPE) pipes. Based on the information, all CMP pipes on Cal Poly campus were assumed to have been replaced by PVC or HDPE pipes. As such, the $n$ values recommended for plastic pipes (Table 4) by the California Department of Transportation (Caltrans) was used for all storm pipes on campus. 
Table 3 Manning's N value for channels (ASCE, 1982)

\begin{tabular}{|l|l|}
\hline Channel Type & Manning's $\mathrm{n}$ \\
\hline Lined Channels & $0.013-0.017$ \\
\hline Asphalt & $0.012-0.018$ \\
\hline Brick & $0.011-0.020$ \\
\hline Concrete & $0.020-0.035$ \\
\hline Rubble or riprap & $0.030-0.40$ \\
\hline Vegetal \\
\hline Excavated or dredged \\
\hline Earth, straight and uniform & $0.020-0.030$ \\
\hline Earth, windy, fairly uniform & $0.025-0.040$ \\
\hline Rock & $0.030-0.045$ \\
\hline Unmaintained & $0.050-0.140$ \\
\hline Natural channels (minor streams, top width at flood stage $<100 \mathrm{ft}$ ) \\
\hline Fairly regular section & $0.030-0.070$ \\
\hline Irregular section with pools & $0.040-0.100$ \\
\hline
\end{tabular}

Table 4 Manning's $n$ valve for various pipe materials (Caltrans, 2014)

850-2

HIGHWAY DESIGN MANUAL

October 4, 2010

Table 851.2

Manning " $n$ " Value for Alternative

Pipe Materials ${ }^{(1)}$

\begin{tabular}{|c|c|c|c|}
\hline $\begin{array}{l}\text { Type of } \\
\text { Conduit }\end{array}$ & & $\begin{array}{l}\text { Recommended } \\
\text { Design Value }\end{array}$ & $\begin{array}{l}\text { "n" Value } \\
\text { Range }\end{array}$ \\
\hline \multicolumn{4}{|l|}{ Corrugated Metal Pipe ${ }^{(2)}$} \\
\hline \multicolumn{4}{|l|}{ (Annular and Helical) ${ }^{(3)}$} \\
\hline $22 / 3^{\prime \prime} \times 1 / 2^{\prime \prime}$ & corrugation & 0.025 & $0.022-0.027$ \\
\hline $3 " x 1^{\prime \prime}$ & $n$ & 0.028 & $0.027-0.028$ \\
\hline $5 " \times 1 "$ & $"$ & 0.026 & $0.025-0.026$ \\
\hline $6 " \times 2 "$ & $n$ & 0.035 & $0.033-0.035$ \\
\hline $9^{\prime \prime} \times 21 / 2 "$ & $"$ & 0.035 & $0.033-0.037$ \\
\hline \multicolumn{4}{|l|}{ Concrete Pipe } \\
\hline Pre-cast & & 0.012 & $0.011-0.017$ \\
\hline Cast-in-place & & 0.013 & $0.012-0.017$ \\
\hline Concrete Box & & 0.013 & $0.012-0.018$ \\
\hline \multicolumn{4}{|l|}{ Plastic Pipe (HDPE and PVC) } \\
\hline Smooth Interior & & 0.012 & $0.010-0.013$ \\
\hline Corrugated Interior & & 0.022 & $0.020-0.025$ \\
\hline \multicolumn{4}{|l|}{ Spiral Rib Metal Pipe } \\
\hline 3/4" (W) x 1" (D)@111/2" o/c & & 0.013 & $0.011-0.015$ \\
\hline 3/4" (W) x 3/4" (D)@71/2" o/c & & 0.013 & $0.012-0.015$ \\
\hline 3/4" (W) x 1" (D)@81/2" o/c & & 0.013 & $0.012-0.015$ \\
\hline Composite Steel Spiral Rib Pipe & & 0.012 & $0.011-0.015$ \\
\hline Steel Pipe, Ungalvanized & & 0.015 & - \\
\hline Cast Iron Pipe & & 0.015 & -- \\
\hline Clay Sewer Pipe & & 0.013 & - \\
\hline Polymer Concrete Grated Line Drain & & 0.011 & $0.010-0.013$ \\
\hline
\end{tabular}




\subsubsection{Depression Storage for Impervious and Pervious Areas}

Depression storage is another parameter that has to be defined for each subcatchment. Depression storage refers to the volume of rainfall that can be retained by the depressions and pits in the land and must be met before runoff forms. Since the majority of the pervious area in the model is lawn and grassland, depression storage recommended for lawns was used for pervious areas. Likewise, the depression storage value recommended for impervious surfaces (Table 5 ) is used for impervious areas.

Table 5 Depression storage for different types of surfaces (ASCE 1992)

\begin{tabular}{|l|l|l|}
\hline Surface & Depression Storage (Inches) & Depression Storage $(\mathrm{mm})$ \\
\hline Impervios Surface & $0.05-0.10$ & $1.25-2.50$ \\
\hline Lawns & $0.10-0.20$ & $2.50-5.0$ \\
\hline Pasture & 0.2 & 5 \\
\hline Foster Litter & 0.3 & 8 \\
\hline
\end{tabular}

\subsubsection{Model Calibration}

The Sensitivity-Based Radio Tuning Calibration (SRTC) tool was used for model calibration. Before running the SRTC tool, attributes must be assigned an uncertainty range if they are to be modified. For this study, $\mathrm{CN}$ and subcatchment width were considered for calibration, and therefore, uncertainties were assigned for both parameters.

Hourly rainfall data from the California Irrigation Management Information System (CIMIS) at station 52 (located at Cal Poly Campus) and the streamflow measurements taken on March 2nd and March 21st were used for the calibration. PCSWMM simulation was performed from February 25, 2018 to April 
08,2018 to ensure that runoff from the subcatchments can be fully captured and to prevent high continuity error (PCSWMM Support, 2018). The goal of the calibration process is to match the modeled and the observed time series closely. However, the measured streamflow is not adequate to perform complete calibration for this study. As such, the "calibration effort" undertaken in this study should be considered as only a cursory effort at improving the model. More streamflow monitoring effort is needed to further improve the model. The result of the calibration will be described in chapter 4 .

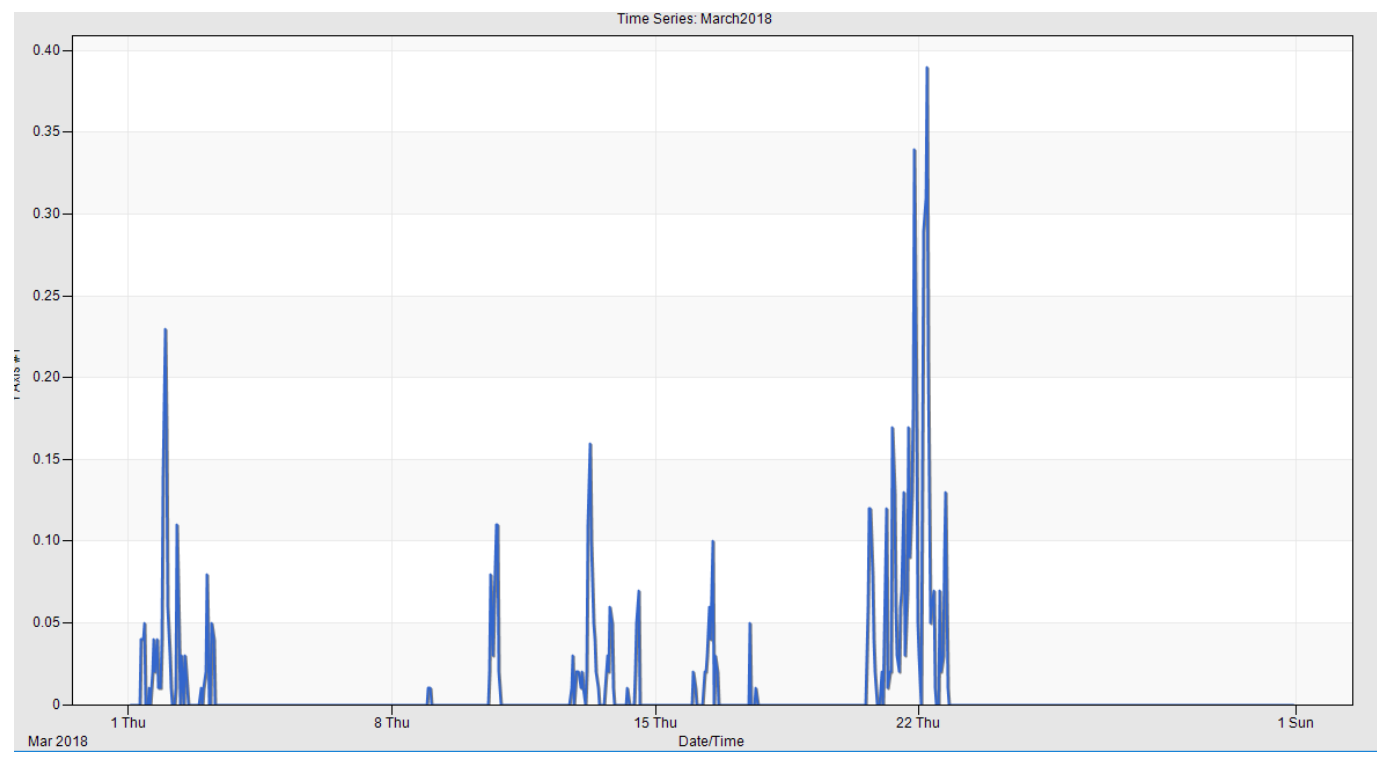

Figure 22 The time series data from CIMIS

\subsubsection{LID Simulation for the Engineering Project Facilities and New Student Housing}

According to Cal Poly Mater Plan, Engineering projects facilities will be built on the $\mathrm{H}-2$ parking lot close to the Kennedy library. The project site is approximately $45,000 \mathrm{ft} 2$. The second project site is the new student housing planned for 
freshmen and will be located at the current $\mathrm{R}-1$ and $\mathrm{H}-1$ parking lots. The project site is approximately $300,000 \mathrm{ft} 2$ which will occupy approximate 96 percent of the $\mathrm{H}-1$ and $\mathrm{R}-1$ lots combined. Since not enough information is available about the projects at this moment, the square footages are assumed to be the buildings foot-print. The rest of the existing parking lots (i.e., $H-2, R-1$, and $H-1$ ) will be assumed to be replaced by both pervious and impervious areas.

For this study, the PCSWMM model developed for Cal Poly Campus was used to analyze the effectiveness of implementing LIDs to reduce hydrologic impacts of the two planned projects previously described. Bioretention cell (BRC) and permeable pavements (PP) were the LID types evaluated. BRC is increasingly used as an urban stormwater management practice across the United States. Benefits of using BRCs include increasing water storage, restricting flow, infiltration, and evapotranspiration. BRC has the potential to improve water quality and water balance which can positively impact the urban infrastructure (Davis et al., 2012). A typical cross-section of BRC is shown in Figure 23. 


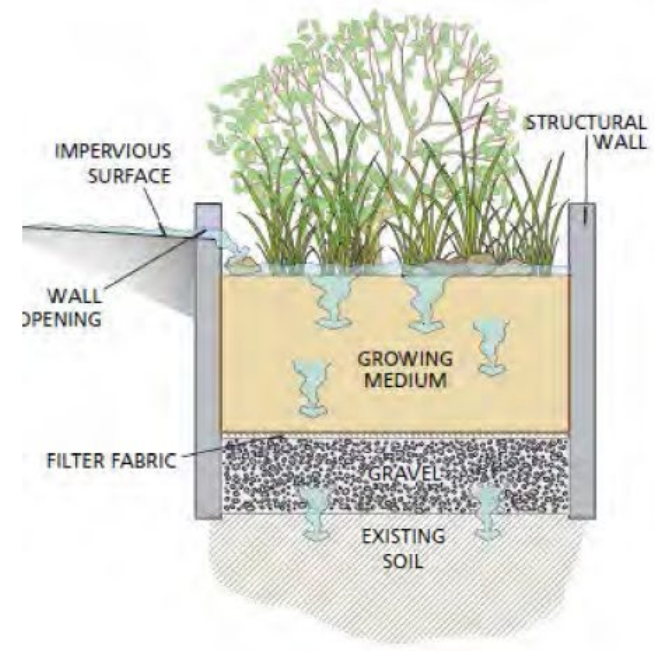

(A)

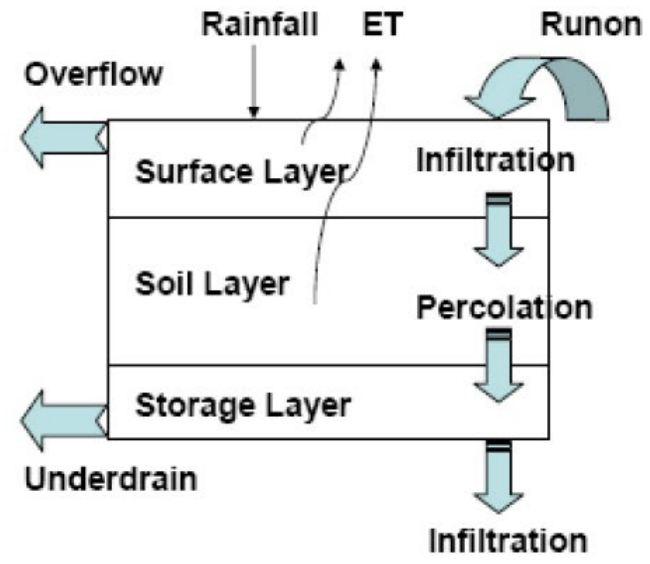

(B)

Figure 6-1 A typical bio-retention cell

Figure 23 The typical cross-section of a BRC (Rossman, \& Huber, 2016)

Compared with the traditional stormwater management technologies such as asphalt pavements, PP systems can effectively reduce runoff quantity, lower peak flowrate, delay peak flow and minimize associated pollutants because of their high infiltration rate according to pervious research (Brattebo, \& Booth, 2003; Collins, Hunt, \& Hathaway, 2008). Additionally, PPs regardless of the type can accomplish the hydrological goal (Booth \& Leavitt, 1999). Therefore, the types of permeable pavements would not be discussed in this study. A typical detail of PPs is shown in Figure 24 Block paver PPs were assumed, and parameters recommended for this PP type was assigned to PCSWMM. Clogging factor for PPs was ignored since the simulation period was 43 days which was relatively short (PCSWMM Support). 


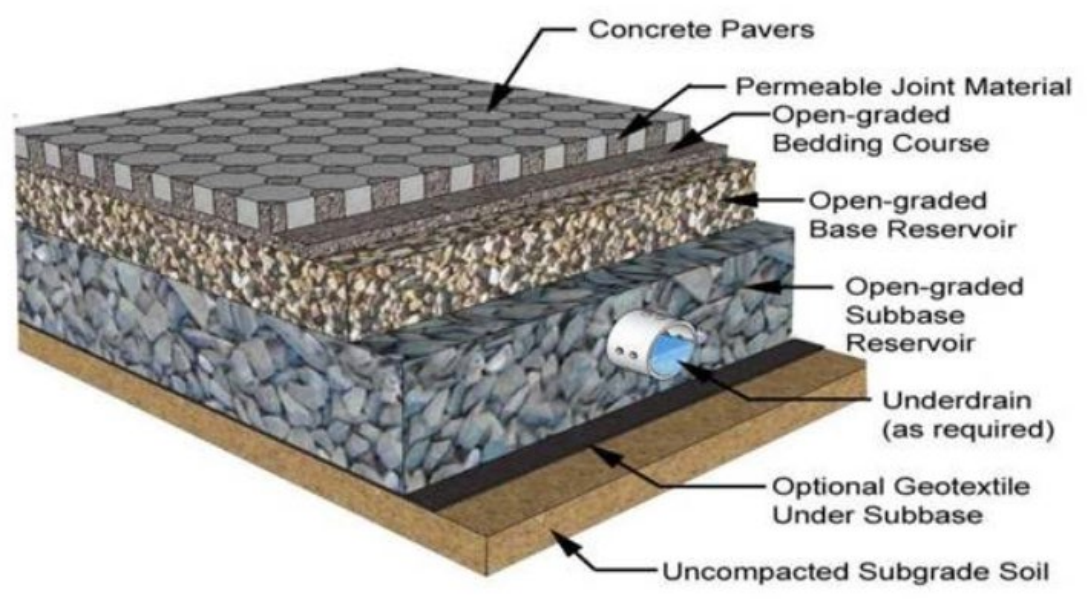

Figure 24 The typical detail of permeable pavements (Virginia DEQ, 2011)

Atchison, Potter, \& Severson (2006) suggested that bioretention areas can achieve maximum groundwater recharge when the bioretention size is about 15 percent of the impervious area. Dussaillant et al. (2004) also indicated that the $\mathrm{BRC}$ provides optimized groundwater recharge when the size of the BRC is about 10 to 20 percent of the contributing impervious surfaces. In this study, 20 percent of the non-rooftop impervious surface was assigned to be the LID size.

BRC could not be installed at entre open space since a certain percent of the open space needed to be used for walkways and other on-site facilities. BRC parameters were obtained from the Storm Water Management Model Reference Manual Volume III - Water Quality (Rossman, \& Huber, 2016). Each parameter has a range of recommended value as shown in Table 6 and Table 7. Average values were used for the LID designs.

Four assumptions were made for the LID design due to lack of data:

The slope of the LID surface $w$ is same as the slope of the subcatchment. 
LID subcatchments are separate from the original subcatchment. LIDs are not placed in the existing subcatchment as shown in Figure 25.

Underdrains have a 4-inch diameter, and the drain coefficient was calculated by using Equation 3.

Native soil seepage rate data was not available for the project sites. The default seepage rate in PCSWMM was used for the LID designs. The seepage rate of a site's native soil affects the infiltration rate from the bottom layer of a LID device to the native soil.

Table 6 LID parameters for SWMM modeling - BRC (Rossman, \& Huber, 2016)

\begin{tabular}{|l|c|}
\hline Parameter & Range \\
\hline Maximum Freeboard, inches $\left(D_{1}\right)$ & $6-12$ \\
\hline Surface Void Fraction $\left(\phi_{1}\right)$ & $0.8-1.0$ \\
\hline Soil Layer Thickness, inches $\left(D_{2}\right)$ & $24-48$ \\
\hline Soil Properties: & \\
\hline \multicolumn{1}{|c|}{ Porosity $\left(\phi_{2}\right)$} & $0.45-0.6$ \\
\hline \multicolumn{1}{|c|}{ Field Capacity $\left(\theta_{F C}\right)$} & $0.15-0.25$ \\
\hline \multicolumn{1}{|c|}{ Wilting Point $\left(\theta_{W P}\right)$} & $0.05-0.15$ \\
\hline Saturated Hydraulic Conductivity, in/hr $\left(K_{2 S}\right)$ & $2.0-5.5$ \\
\hline Wetting Front Suction Head, inches $\left(\psi_{2}\right)$ & $2-4$ \\
\hline Percolation Decay Constant $(H C O)$ & $30-55$ \\
\hline Storage Layer Thickness, inches $\left(D_{3}\right)$ & $6-36$ \\
\hline Storage Void Fraction $\left(\phi_{3}\right)$ & $0.2-0.4$ \\
\hline Capture Ratio $\left(R_{L I D}\right)$ & $5-15$ \\
\hline Soil Property & Value \\
\hline Porosity $\left(\phi_{2}\right)$ & 0.52 \\
\hline Field Capacity $\left(\theta_{F C}\right)$ & 0.15 \\
\hline Wilting Point $\left(\theta_{W P}\right)$ & 0.08 \\
\hline Saturated Hydraulic Conductivity, in/hr $\left(K_{2 S}\right)$ & 4.7 \\
\hline Percolation Decay Constant $(H C O)$ & 39.3 \\
\hline Wetting Front Suction Head, inches $\left(\psi_{2}=3.23\left(K_{2 S}\right)^{-0.328}\right)$ & 1.9 \\
\hline
\end{tabular}


Table 7 LID parameters for SWMM modeling - PPs (Rossman, \& Huber, 2016)

\begin{tabular}{|c|c|}
\hline Parameter & Range \\
\hline Surface Depression Storage, inches $\left(D_{1}\right)$ & $0-0.1$ \\
\hline Surface Void Fraction $\left(\phi_{1}\right)$ & 1.0 \\
\hline Pavement Thickness, inches $\left(D_{4}\right)$ & $3-8$ \\
\hline \multicolumn{2}{|l|}{ Continuous Pavement: } \\
\hline Porosity $\left(\phi_{4}\right)$ & $0.15-0.25$ \\
\hline Permeability, in $/ \mathrm{hr}\left(K_{4}\right)$ & $28-1750$ \\
\hline Surface Opening Fraction $\left(1-F_{4}\right)$ & 0 \\
\hline \multicolumn{2}{|l|}{ Block Pavers: } \\
\hline Porosity $\left(\phi_{4}\right)$ & $0.1-0.4$ \\
\hline Permeability, in $/ \mathrm{hr}\left(K_{4}\right)$ & $5-150$ \\
\hline Surface Opening Fraction $\left(1-F_{4}\right)$ & $0.08-0.10$ \\
\hline \multicolumn{2}{|l|}{ Sand Filter Layer: } \\
\hline Thickness, inches $\left(D_{2}\right)$ & $8-12$ \\
\hline Porosity $\left(\phi_{2}\right)$ & $0.25-0.35$ \\
\hline Field Capacity $\left(\theta_{F C}\right)$ & $0.15-0.25$ \\
\hline Wilting Point $\left(\theta_{W P}\right)$ & $0.05-0.10$ \\
\hline Saturated Hydraulic Conductivity, in $/ \mathrm{hr}\left(K_{2 S}\right)$ & $5-30$ \\
\hline Wetting Front Suction Head, inches $\left(\psi_{2}\right)$ & $2-4$ \\
\hline Percolation Parameter $(\mathrm{HCO})$ & $30-55$ \\
\hline Storage Layer Thickness, inches $\left(D_{3}\right)$ & $6-36$ \\
\hline Storage Void Fraction $\left(\phi_{3}\right)$ & $0.2-0.4$ \\
\hline Capture Ratio $\left(R_{L I D}\right)$ & $0-5$ \\
\hline
\end{tabular}




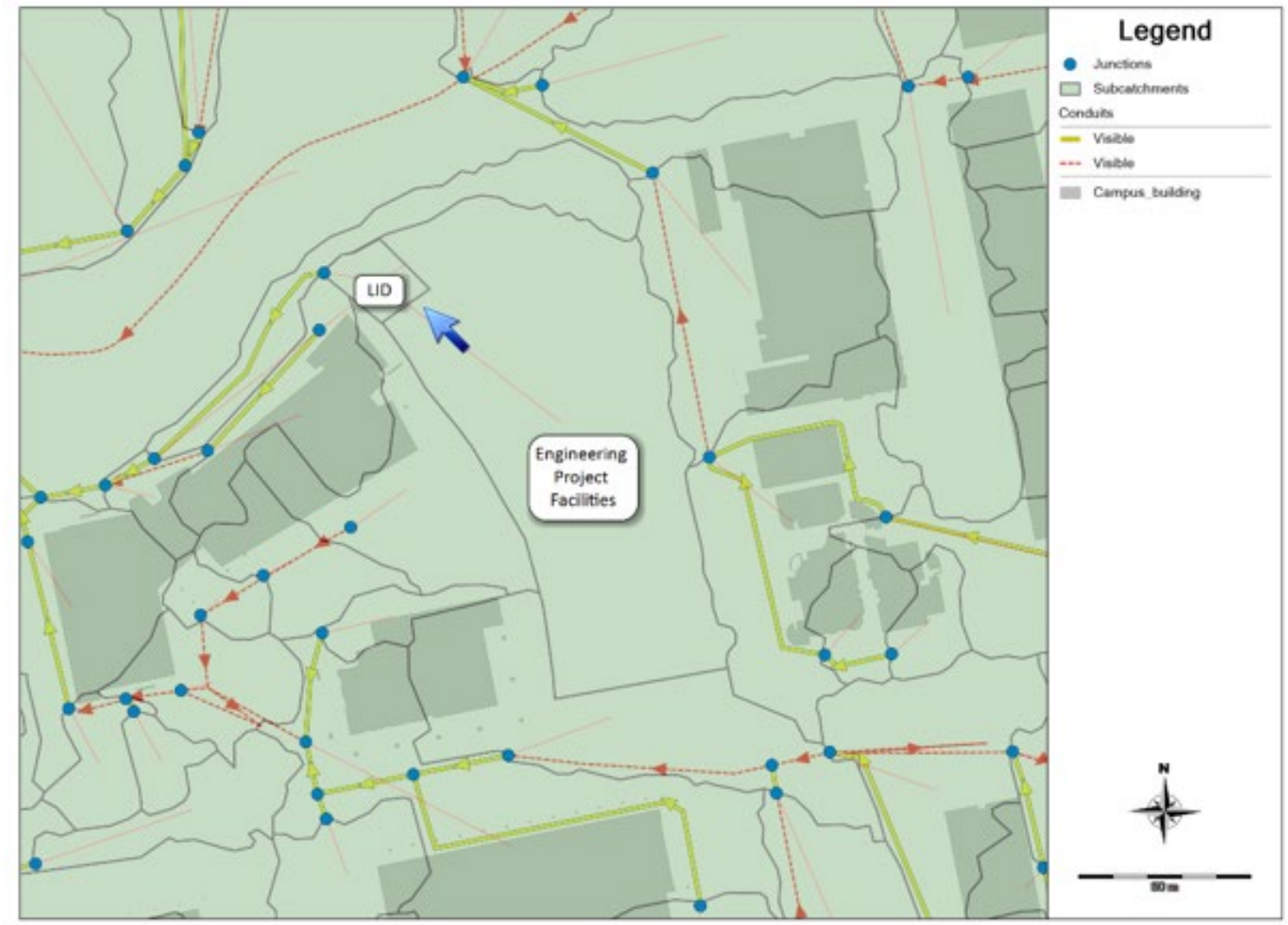

Figure 25 Proposed project site for Engineering Project Facilities was drained to the LID subcatchment which was separated from the project site

$$
C_{\text {LID }}=43200 \sqrt{\frac{g}{6}} C_{d} \frac{A_{\text {orif }}}{A_{\text {LID }}}
$$

Equation 3 


\section{Results}

The study results will be discussed in this chapter including the calibration results and LID simulation results. The calibration results were analyzed by comparing the observed peak flow from the stream measurement with the simulated peak flow in PCSWMM at the same time and location. The LID results were analyzed in two approaches. The first approach was to compare the peak flow and total runoff volume between the current site and master plan with LID condition. The second approach was to compare the inflow and outflow through the selected LID devices.

\subsection{Calibration Result}

As shown in Figure 26, the red line shows the data collected from the streamflow monitoring; the blue and green lines indicated the initial and calibrated streamflow hydrographs, respectively. Only green and red lines are visible in Figure 26 because the model and calibrated results are the same before calibration. As shown in Figure 27, the calibrated time series (green line) does not overlap with the initial time series (blue line) after the model parameters were changed, and the black line shows the simulation results after re-running the model with the adjusted parameters. The calibration focused mainly on matching peak discharge (Oudin, Salavati, Furusho-Percot. Ribstein, \& Saadi, 2018).

After verifying the time series with the calibrated data, PCSWMM provides error statistics between the calibrated and observed flows. As shown in Table 8 and Equation 4, the integral square error (ISE) which integrates the square of the 
errors over time improved from poor to fair after the calibration. Other errors statistics also demonstrated that the calibration improved the model predictions.

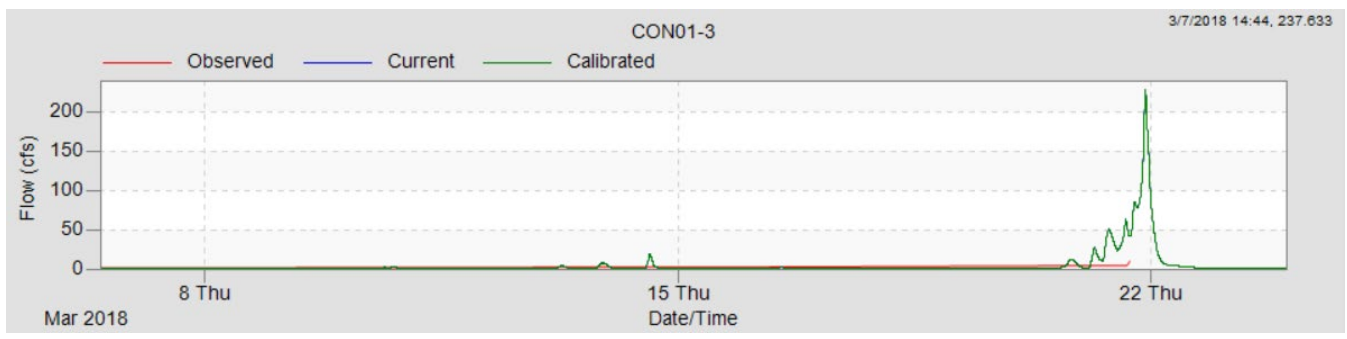

Figure 26 Streamflow time series at the monitoring site before calibration

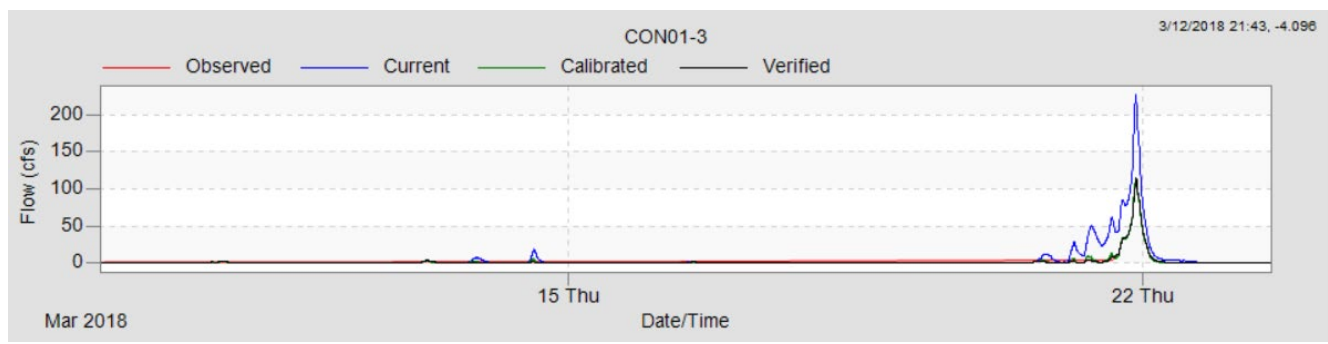

Figure 27 Streamflow time series at the monitoring site after calibration

Table 8 The error statistics derived from measured and simulated streamflow

\begin{tabular}{|llll|}
\hline Error: & Current & Calibrated & Verified \\
ISE rating & Poor & Poor & Fair \\
ISE & 27.5 & 26.6 & 24.1 \\
NSE & 0.258 & 0.304 & 0.431 \\
$\mathrm{R}^{2}$ & 0.898 & 0.879 & 0.905 \\
SEE & 2.38 & 2.31 & 2.09 \\
LSE & 34.1 & 31.9 & 26.1 \\
LSE dim & 4.1 & 4.44 & 4.03 \\
RMSE & 5.46 & 5.11 & 4.38 \\
RMSE dim & 0.254 & 0.249 & 0.256 \\
\hline
\end{tabular}




$$
\text { ISE }=\frac{\sqrt{\sum\left(y_{o b s}^{i}-y_{\text {como }}^{i}\right)^{2}}}{\sum y_{\text {obs }}^{i}}
$$

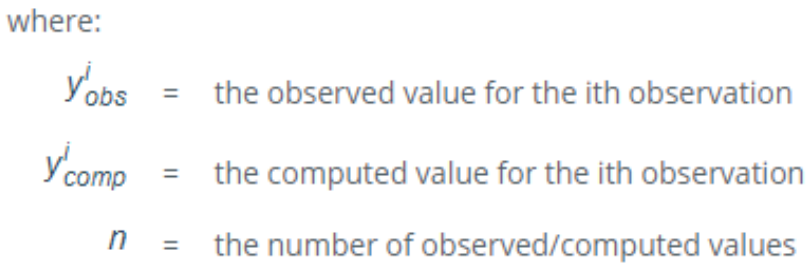

Equation 4

The calibration was performed many times to reduce the percentage error between the calibrated and measured data. Only the first two and the last calibration results were shown in Table 10. As shown in Table 9, six data points were collected during the streamflow monitoring survey. The measured peak discharge was 9.28 cubic feet per second (cfs), and the predicted peak discharge at the identical time and location was $41.63 \mathrm{cfs}$. In other words, the modeled peak discharge was approximately 4.5 times higher than the measured peak discharge. After calibrating the subcatchment width and CN attributes with SRTC tool, the percentage difference between the measured and calibrated peak discharge reduced as shown in Table 10. The percentage error between the observed and the first calibration attempt in the highlighted row was 75.77. After the second calibration was performed, the percentage error lowered to 20.04, and the percentage error was further reduced to 0.93 after many attempts. 
Table 9 Comparison of the observed and predicted streamflow

\begin{tabular}{|r|l|r|r|r|}
\hline \multicolumn{3}{|c|}{ Observation Data } & \multicolumn{2}{c|}{ Original Model Result } \\
\hline Date & Time & Measured Discharge (cfs) & Modeled Discharge (cfs) & Percentage Error (\%) \\
\hline $3 / 2 / 2018$ & $6: 35 \mathrm{AM}$ & 2.50 & 0.10 & 96.19 \\
\hline $3 / 2 / 2018$ & $7: 35 \mathrm{AM}$ & 1.17 & 1.73 & 48.26 \\
\hline $3 / 16 / 2018$ & $8: 45 \mathrm{AM}$ & 1.89 & 0.46 & 75.66 \\
\hline $3 / 16 / 2018$ & $9: 30 \mathrm{AM}$ & 0.65 & 65.55 \\
\hline $3 / 21 / 2018$ & $3: 20 \mathrm{PM}$ & 1.90 & 58.67 & 1212.43 \\
\hline $3 / 21 / 2018$ & $4: 35 \mathrm{PM}$ & 4.47 & 41.63 & 348.60 \\
\hline
\end{tabular}

Table 10 Comparison of the observed and predicted streamflow

\begin{tabular}{|r|r|r|r|r|r|}
\hline \multicolumn{2}{|c|}{ First Modification Result } & \multicolumn{2}{|c|}{ Second Modification Result } & \multicolumn{2}{|c|}{ Last Modification Result } \\
\hline Modified Discharge (cfs) & Percentage Error (\%) & Modified Discharge (cfs) & Percentage Error (\%) & Modified Discharge (cfs) & Percentage Error (\%) \\
\hline 0.10 & 95.90 & 0.10 & 95.90 & 0.1 & 96.00 \\
\hline 1.81 & 54.50 & 1.81 & 54.50 & 1.7931 & 53.26 \\
\hline 0.43 & 77.48 & 0.43 & 77.48 & 0.423 & 77.62 \\
\hline 0.62 & 67.47 & 0.62 & 67.47 & 0.6146 & 67.65 \\
\hline 2.52 & 43.57 & 5.02 & 12.35 & 6.4008 & 43.19 \\
\hline 2.25 & 75.77 & 7.42 & 20.04 & 9.194 & 0.93 \\
\hline
\end{tabular}

\subsection{LID Simulation Results}

The Subcatchment where the LIDs are located, the subcatchment where the proposed projects are located, and the junction downstream of the LID subcatchment were selected to analyze the effectiveness of LIDs. The LID performance analysis targeted on two aspects: comparison of the runoff volume and peak flow for the current condition and the proposed condition with LIDs; inflow and outflow for the LIDs. The simulation period was from 2/25/2018 to 4/8/2018 which covered the time frame when stream data was collected. For scenarios were analyzed in this study are listed as follows:

- Engineering Project Facilities with BRC

- Engineering Project Facilities with PPs

- New Student Housing with BRC

- New Student Housing with PPs 


\subsubsection{BRC Simulation - Engineering Project Facilities}

As shown in Table 11, implementing BRCs as part of the proposed project would reduce peak flow by approximately $0.2 \mathrm{cfs}(26.9 \%)$ and total runoff volume by 44207 cubic feet $(82.9 \%)$ compared to the current site condition. Peak flow and total runoff reduction data from the literature can be useful to evaluate the accuracy of the simulated performance reduction. Most of these studies compared peak flow and runoff volume based on inflow and outflow through the LID rather than comparing the current conditions to the proposed site conditions.

Inflow to the LID and outflow from the LID were analyzed to evaluate the effectiveness of the LID. As shown in Table 12, the BRC reduced peak flow by approximately $0.12 \mathrm{cfs}(17.3 \%)$ and total runoff volume by $47000 \mathrm{cf}(98.1 \%)$. Table 13 and Table 14 summarize peak flow and volume reductions from the literature based on field observation, experiment, and modeling to examine LID performances. Data for Rain Gardens was included in both tables since Rain Gardens provide similar functionalities as BRC and can indicate peak flow and volume reduction potential of BRCs. UNHSC (2006) demonstrated average peak flow reduction of $85 \%$ using BRCs for large park lots; Davis (2008) indicated that 40-48\% peak flow reduction by installing BRCs to treat mostly parking lot and roadway. Other studies also showed different ranges of peak flow reduction rate through BRCs. Overall, peak flow reduction rates ranging from 38 to 90 percent have been reported in the literature. 
Regarding total runoff volume reduction by BRCs, Aad, Suidan, \& Shuster (2010) modeled two rain gardens using EPA-SWMM. Up to 38\% runoff volume reduction was achieved if the size of the rain garden was set to $3.9 \%$ of the roof area, and $100 \%$ reduction rate was simulated if the rain garden was three times bigger. Davis (2008) also reported 55 to 70 percent volume reduction due to exfiltration by BRCs.

Compared to the peak flow and total volume reductions reported in the literature, the BRC performances simulated by this study for peak flow reduction was low while total runoff volume reduction was high.

Table 11 The peak flow and total inflow volume of the current site condition (Current for SA) and proposed site condition (Isolated LID)

\begin{tabular}{|l|c|c|}
\hline \multicolumn{3}{|c|}{ From 2/25/2018 1:14:36 AM to 4/8/2018 10:15:24 PM (42.88 days) } \\
\hline & J-EFP Isolated LID & J-EFP Sewershed_3 Correction of Current Condition \\
\hline Maximum Total inflow (cfs) & 0.5634 & 0.7705 \\
\hline Minimum Total inflow (cfs) & 0 & 0 \\
\hline Mean Total inflow (cfs) & 0.002706 & 0.01763 \\
\hline Duration of Exceedances $(\mathrm{h})$ & 935.5 & 840 \\
\hline Duration of Deficits $(\mathrm{h})$ & 924.6 & 7.983 \\
\hline Number of Exceedances & 1 & 1 \\
\hline Number of Deficits & 3 & 53320 \\
\hline Volume of Exceedances $\left(\mathrm{ft}^{3}\right)$ & 9113 & 0 \\
\hline Volume of Deficits $\left(\mathrm{ft}^{3}\right)$ & 0 & 53320 \\
\hline Total Total inflow $\left(\mathrm{ft}^{3}\right)$ & 9113 & 1 \\
\hline
\end{tabular}




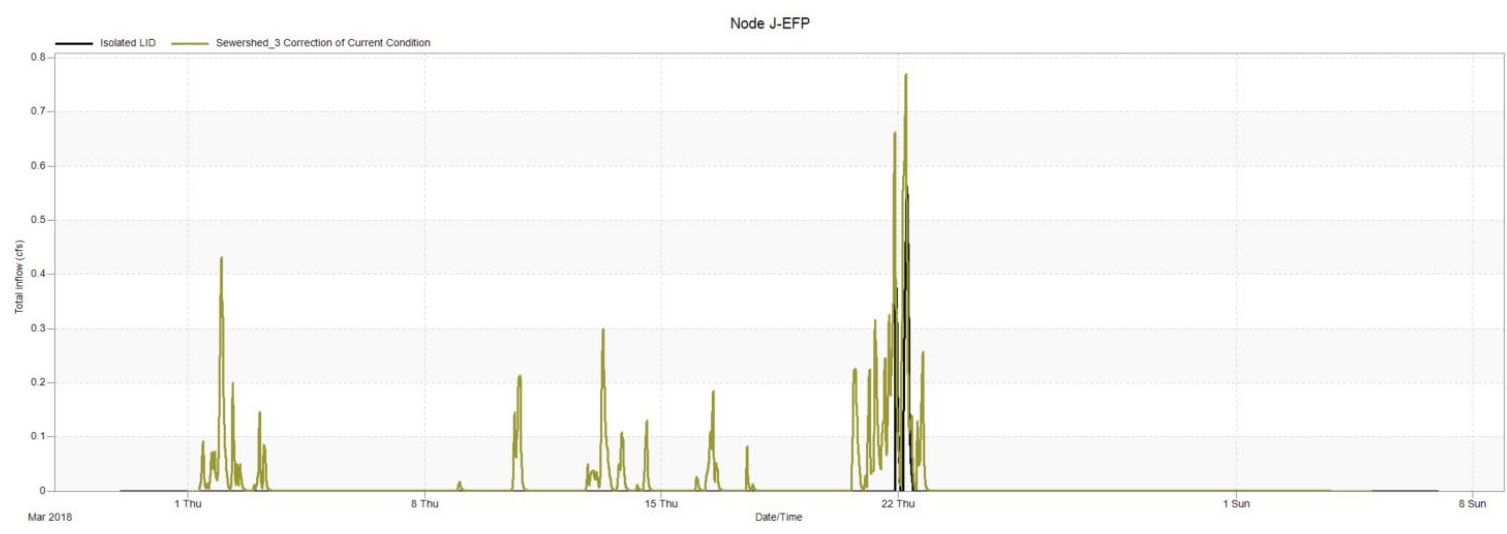

Figure 28 The inflow of the current site condition (Current for SA) and the master plan condition (Isolated LID)

Table 12 The inflow (S-SEP) and outflow (S-EFP-1) through the BRC

\begin{tabular}{|l|c|c|}
\hline \multicolumn{3}{|c|}{ From 2/25/2018 1:14:36 AM to 4/8/2018 10:15:24 PM (42.88 days) } \\
\hline & S-EFP & S-EFP-1 \\
\hline Maximum Runoff (cfs) & 0.6811 & 0.5634 \\
\hline Minimum Runoff (cfs) & 0 & 0 \\
\hline Mean Runoff (cfs) & 0.01424 & 0.002706 \\
\hline Duration of Exceedances (h) & 935.5 & 935.5 \\
\hline Duration of Deficits (h) & 728.9 & 924.6 \\
\hline Number of Exceedances & 1 & 1 \\
\hline Number of Deficits & 10 & 3 \\
\hline Volume of Exceedances ( $\mathrm{ft}^{3}$ ) & 47970 & 9113 \\
\hline Volume of Deficits ( $\mathrm{ft}^{3}$ ) & 0 & 0 \\
\hline Total Runoff $\left(\mathrm{ft}^{3}\right.$ ) & 47970 & 9113 \\
\hline
\end{tabular}

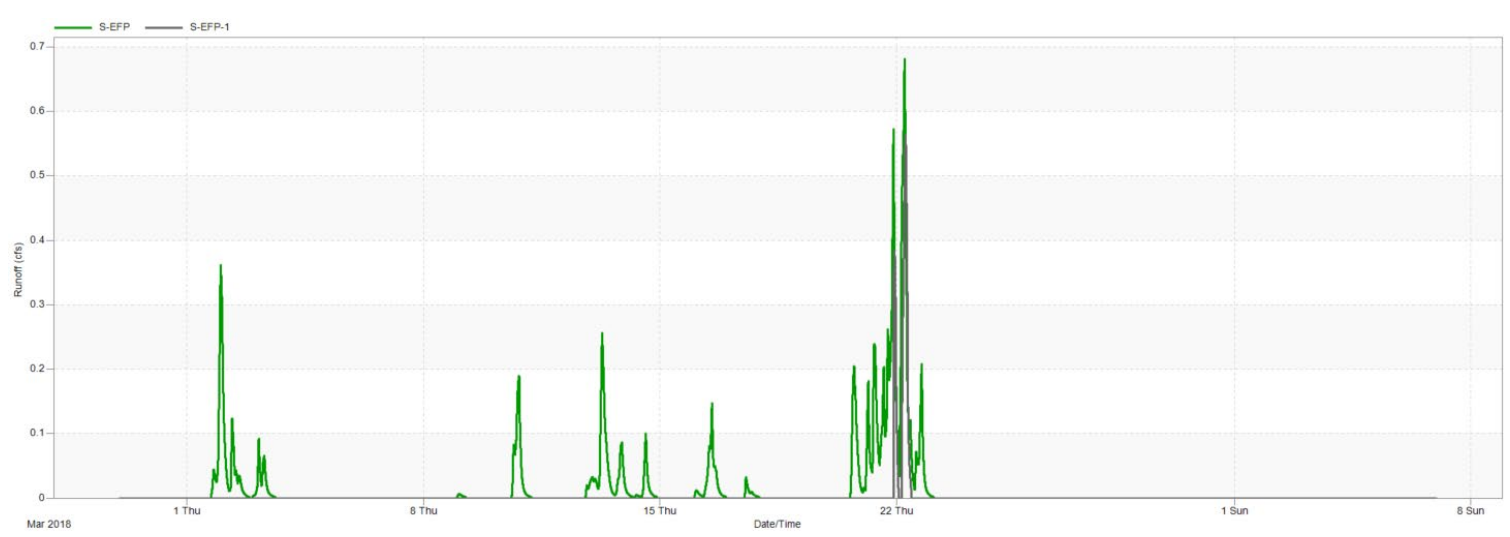

Figure 29 The inflow (S-SEP) and outflow (S-EFP-1) through the BRC 
Table 13 The peak flow reduction rate by implementing RGs or BRCs through field experiment or computer modeling

\begin{tabular}{|c|c|c|}
\hline Site Condition & $\begin{array}{c}\text { Peak Flow Reduction } \\
\text { Rate (\%) }\end{array}$ & Reference \\
\hline Large Parking Area & Average 85 & (UNHSC, 2006) \\
\hline $\begin{array}{c}\text { The median field for mostly } \\
\text { parking lot and roadway }\end{array}$ & $40-48$ & (Davis, 2008) \\
\hline $\begin{array}{c}\text { Other BMPs similar to BRC } \\
\text { called an ecology ditch and a } \\
\text { partial exfiltration reactor }\end{array}$ & 90 (Maximum) & $\begin{array}{c}\text { (Barber et al. 2013; } \\
\text { Sansalone, \& Teng 2004; } \\
\text { 2005) }\end{array}$ \\
\hline Rain Garden in general & Provide runoff control & (Dietz \& Clausen, 2005) \\
\hline $\begin{array}{c}\text { The rain garden size was } \\
3.9 \% \text { of the rooftop area }\end{array}$ & 38 & $\begin{array}{c}\text { (Aad, Suidan, \& Shuster, } \\
\text { 2010) }\end{array}$ \\
\hline $\begin{array}{c}\text { Typical peak flow reduction } \\
\text { for BRCs }\end{array}$ & $44-63 \%$ & (Davis, 2008) \\
\hline
\end{tabular}

Table 14 The runoff volume reduction rate by implementing RGs or BRCs through field experiment or computer modeling

\begin{tabular}{|c|c|c|}
\hline Site Condition & $\begin{array}{c}\text { Runoff Volume } \\
\text { Reduction (\%) }\end{array}$ & Reference \\
\hline $\begin{array}{c}\text { The rain garden size was 3.9\% of } \\
\text { the rooftop area }\end{array}$ & 38 & $\begin{array}{c}\text { (Aad, Suidan, \& } \\
\text { Shuster, 2010) }\end{array}$ \\
\hline $\begin{array}{c}\text { The rain garden size was 11.7\% } \\
\text { of the rooftop area }\end{array}$ & 100 & $\begin{array}{c}\text { (Aad, Suidan, \& } \\
\text { Shuster, 2010) }\end{array}$ \\
\hline $\begin{array}{c}\text { Through Exfiltration (Bioretention } \\
\text { Cells) }\end{array}$ & $55-70$ & (Davis, 2008) \\
\hline
\end{tabular}

\subsubsection{PPs Simulation - Engineering Project Facilities}

Based on the comparisons of the current site conditions and proposed site condition with PPs, Table 15 shows that the PPs decreased peak flow by approximately $0.13 \mathrm{cfs}(16.4 \%)$ and total runoff volume by $43600 \mathrm{cf}(81.2 \%)$.

The comparison of inflow and outflow through the PPs was performed since most of the studies reported in the literature evaluated the reduction rates based on inflow and outflow through PPs. As shown in Table 16, the PPs decreased peak 
flow by approximately $0.03 \mathrm{cfs}(5.4 \%)$ and total runoff volume by $38200 \mathrm{cf}$ $(79.7 \%)$.

The peak and volume reductions reported in the literature for PPs including those based on field observations and computer modeling were summarized in Table 17. Bean (2005) used a ratio of peak exfiltration to peak rainfall to demonstrate peak reduction rate for PPs. Reductions reported range from 18 to 45 percent for peak flow and 30 to 56 percent of for runoff volume. Rushton (1999) compared runoff from a site with and without PPs and reported a 25 to 90 percent runoff volume reduction when PPs were installed.

Compared to the peak flow and total volume reductions reported in the literature, the PPs performance simulated by this study for peak flow reduction was low while total runoff reduction was consistent with the reduction rate from the literature. 
Table 15 The peak flow and total inflow volume of the current site condition (Correction of Current Condition) and the proposed site condition (Isloated_LID)

From 2/25/2018 1:14:36 AM to 4/8/2018 10:15:24 PM (42.88 days)

\begin{tabular}{|l|c|c|}
\hline & J-EFP Isolated LID & J-EFP Sewershed_3 Correction of Current Condition \\
\hline Maximum Total inflow (cfs) & 0.6444 & 0.7705 \\
\hline Minimum Total inflow (cfs) & 0 & 0 \\
\hline Mean Total inflow (cfs) & 0.002885 & 0.01763 \\
\hline Duration of Exceedances (h) & 935.5 & 840 \\
\hline Duration of Deficits (h) & 925.6 & 7.983 \\
\hline Number of Exceedances & 1 & 1 \\
\hline Number of Deficits & 4 & 53320 \\
\hline Volume of Exceedances ( $\left.\mathrm{ft}^{3}\right)$ & 9717 & 0 \\
\hline Volume of Deficits $\left(\mathrm{ft}^{3}\right)$ & 0 & 53320 \\
\hline Total Total inflow $\left(\mathrm{ft}^{3}\right)$ & 9717 & \\
\hline
\end{tabular}

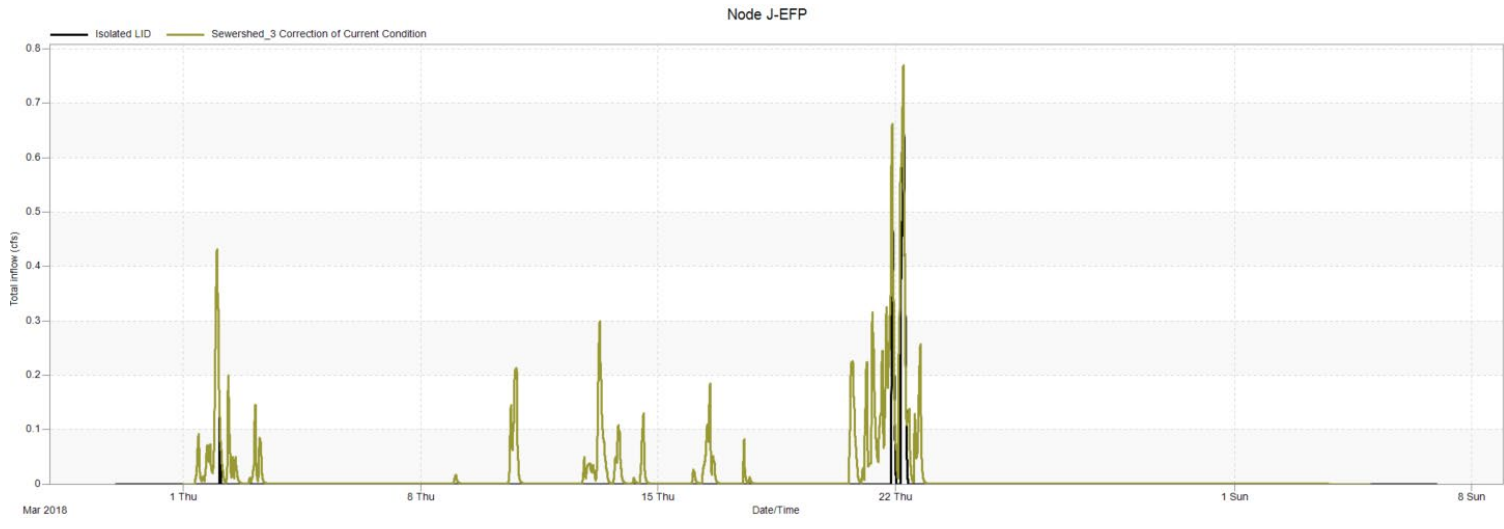

Figure 30 The peak flow and total inflow volume of the current site condition (Correction of Current Condition) and the proposed site condition (Isloated_LID) 
Table 16 The inflow (S-SEP) and outflow (S-EFP-1) through the PPS

\begin{tabular}{|l|c|c|}
\hline \multicolumn{3}{|c|}{ From 2/25/2018 1:14:36 AM to 4/8/2018 10:15:24 PM (42.88 days) } \\
\hline & S-EFP & S-EFP-1 \\
\hline Maximum Runoff (cfs) & 0.6811 & 0.6444 \\
\hline Minimum Runoff (cfs) & 0 & 0 \\
\hline Mean Runoff (cfs) & 0.01424 & 0.002885 \\
\hline Duration of Exceedances (h) & 935.5 & 935.5 \\
\hline Duration of Deficits (h) & 728.9 & 925.7 \\
\hline Number of Exceedances & 1 & 1 \\
\hline Number of Deficits & 10 & 4 \\
\hline Volume of Exceedances ( $\mathrm{ft}^{3}$ ) & 47970 & 9716 \\
\hline Volume of Deficits ( $\mathrm{ft}^{3}$ ) & 0 & 0 \\
\hline Total Runoff $\left(\mathrm{ft}^{3}\right.$ ) & 47970 & 9716 \\
\hline
\end{tabular}

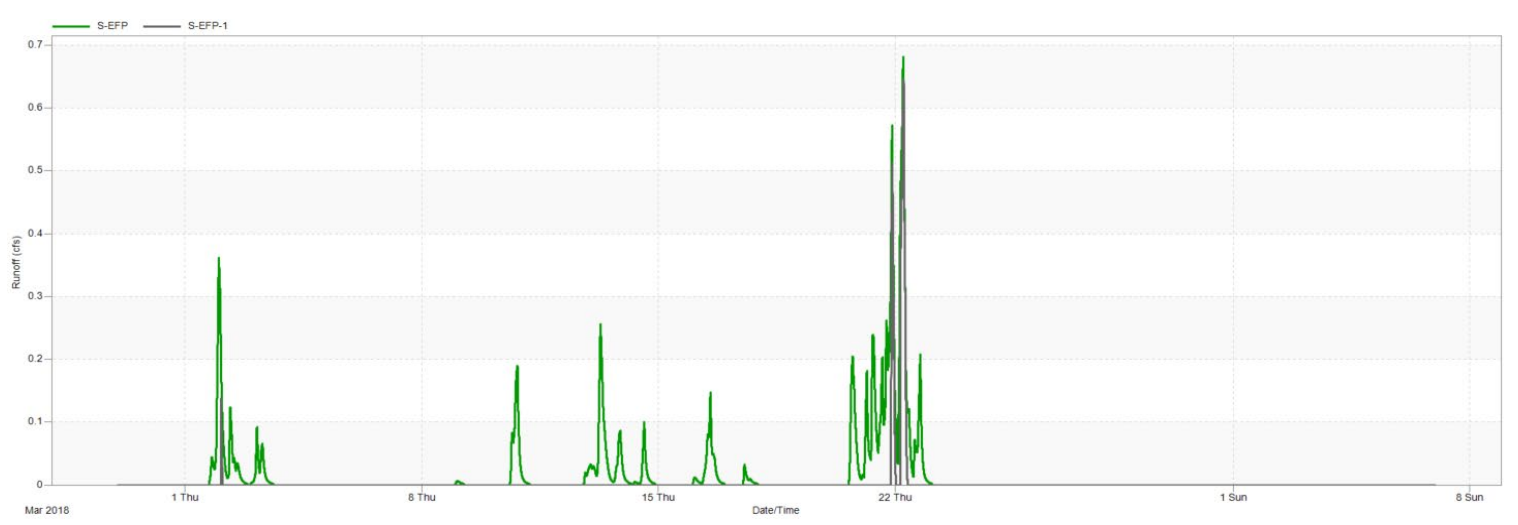

Figure 31 The inflow (S-SEP) and outflow (S-EFP-1) through the PPs.

Table 17 The values of runoff volume and peak flow reduction rate by implementing PPs through field experiment and computer modeling

\begin{tabular}{|c|c|c|}
\hline Site Condition & $\begin{array}{c}\text { Peak Flow Reduction Rate } \\
(\%)\end{array}$ & Reference \\
\hline $\begin{array}{c}\text { Permeable Pavement (Peak } \\
\text { exfiltration rate divided by peak } \\
\text { rainfall rate) }\end{array}$ & $\begin{array}{c}\text { Average } 30 \text { and range } \\
\text { from } 18 \text { to } 45\end{array}$ & (Bean, 2005) \\
\hline Site Condition & $\begin{array}{c}\text { Runoff Volume Reduction } \\
(\%)\end{array}$ & Reference \\
\hline $\begin{array}{c}\text { Permeable Pavement (Runoff } \\
\text { convert to Rainfall Intensity) }\end{array}$ & $\begin{array}{c}44-70 \text { convert to runoff } \\
\text { which equals to } 30 \text { to 56 } \\
\text { reduction }\end{array}$ & (Bean, 2005) \\
\hline A site with and without & $25-90$ & $\begin{array}{c}\text { (Rushton, } \\
\text { 1999) }\end{array}$ \\
\hline
\end{tabular}




\subsubsection{BRC simulation - New Student Housing}

Based on the comparisons of the current site conditions and proposed site condition with a BRC system, Table 18 shows that the BRC reduced peak flow by approximately $0.19 \mathrm{cfs}(10.6 \%)$, and total runoff volume by $21800 \mathrm{cf}(26.9 \%)$.

Comparing inflow and outflow through the BRC as indicated in Table 19, the BRC decreased peak flow by approximately $0.02 \mathrm{cfs}(1.2 \%)$ and total runoff volume by $18200 \mathrm{cf}(23.6 \%)$. As mentioned in Table 13 and Table 14, the peak flow and total runoff volume reduction rate is 38 to 90 and 38 to 100 , respectively.

Compared to the peak flow and total volume reduction from the literature, the BRC performance simulated by this study for both peak flow and total runoff volume reduction were not consistent with the reduction rates from the literature.

Table 18 The runoff and total inflow of the current condition (Current for $S A$ ) and proposed site condition (Isolated LID).

\begin{tabular}{|l|c|c|}
\hline \multicolumn{3}{|c|}{ From 2/25/2018 1:14:36 AM to 4/8/2018 10:15:24 PM (42.88 days) } \\
\hline & J-SA Isolated LID & J-SA Sewershed_3 Current for SA \\
\hline Maximum Total inflow (cfs) & 1.627 & 1.819 \\
\hline Minimum Total inflow (cfs) & 0 & 0 \\
\hline Mean Total inflow (cfs) & 0.01756 & 0.02677 \\
\hline Duration of Exceedances (h) & 935.5 & 840 \\
\hline Duration of Deficits (h) & 866.7 & 7.983 \\
\hline Number of Exceedances & 1 & 1 \\
\hline Number of Deficits & 12 & 80940 \\
\hline Volume of Exceedances ( $\mathrm{ft}^{3}$ ) & 59130 & 0 \\
\hline Volume of Deficits $\left(\mathrm{ft}^{3}\right)$ & 0 & 80940 \\
\hline Total Total inflow $\left(\mathrm{ft}^{3}\right)$ & 59130 & 1 \\
\hline
\end{tabular}




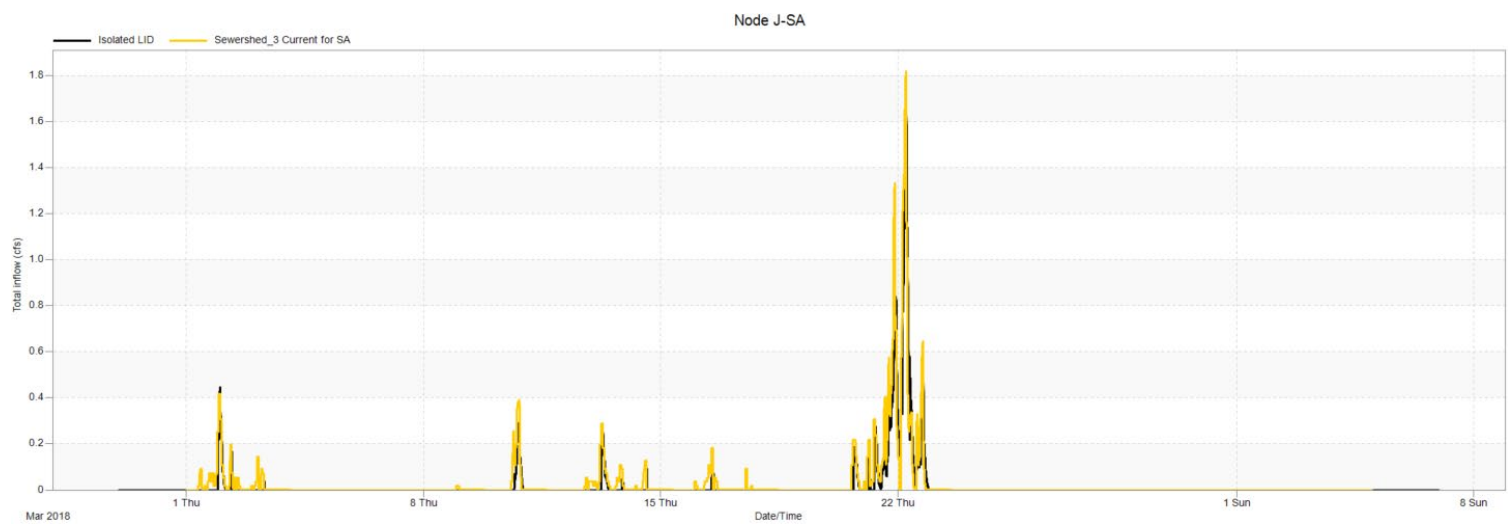

Figure 32 The runoff and total inflow of the current condition (Current for $S A)$ and proposed site condition (Isolated LID)

Table 19 The inflow (S-SA) and outflow (S-SA-1) through the BRCs.

From 2/25/2018 1:14:36 AM to 4/8/2018 10:15:24 PM (42.88 days)

\begin{tabular}{|l|c|c|}
\hline & S-SA & S-SA-1 \\
\hline Maximum Runoff (cfs) & 1.648 & 1.627 \\
\hline Minimum Runoff (cfs) & 0 & 0 \\
\hline Mean Runoff (cfs) & 0.02297 & 0.01756 \\
\hline Duration of Exceedances (h) & 935.5 & 935.5 \\
\hline Duration of Deficits (h) & 797.7 & 866.9 \\
\hline Number of Exceedances & 1 & 1 \\
\hline Number of Deficits & 26 & 12 \\
\hline Volume of Exceedances $\left(\mathrm{ft}^{3}\right)$ & 77360 & 59130 \\
\hline Volume of Deficits $\left(\mathrm{ft}^{3}\right)$ & 0 & 0 \\
\hline Total Runoff $\left(\mathrm{ft}^{3}\right.$ ) & 77360 & 59130 \\
\hline
\end{tabular}

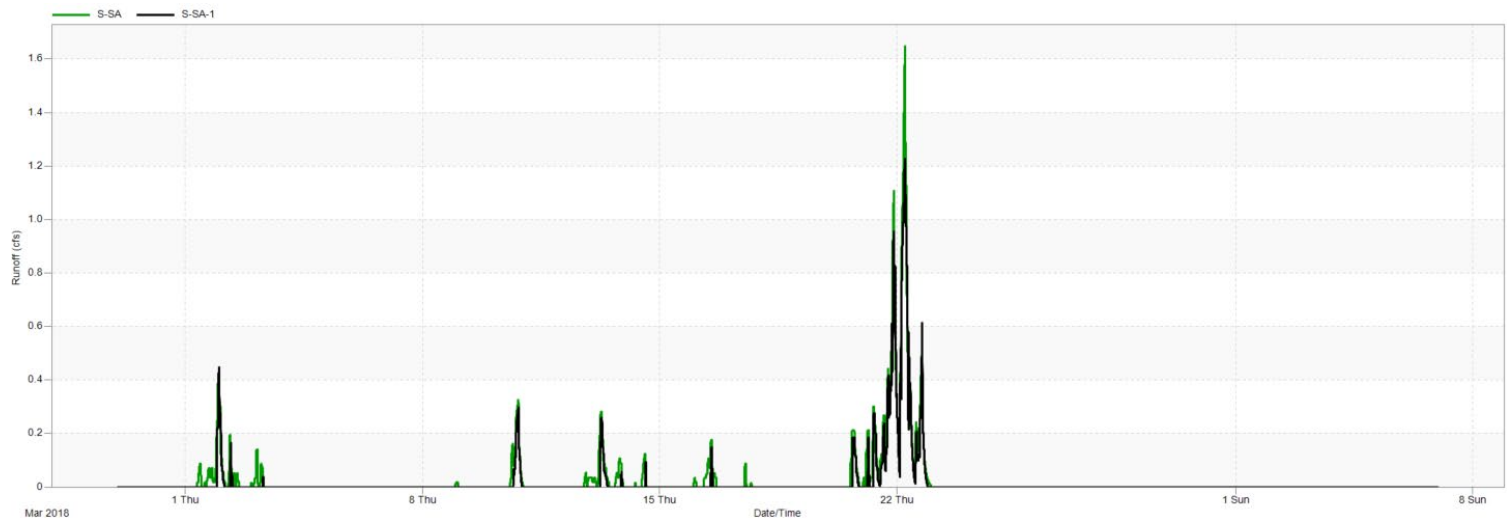

Figure 33 The inflow (S-SA) and outflow (S-SA-1) through the BRCs 


\subsubsection{PPs Simulation - New Student Housing}

Based on the comparisons of the current site conditions and proposed site condition with PPs, Table 20 shows the PPs reduced peak flow by approximately $0.59 \mathrm{cfs}(32.5 \%)$ and total runoff volume by $24500 \mathrm{cf}(30.3 \%)$.

The comparison of inflow and outflow through PPs was performed since most of the studies reported in the literature evaluated the reduction rates based on inflow and outflow through PPs. As shown in Table 21, the PPs reduced peak flow by $0.42 \mathrm{cfs}(25.5 \%)$ and total runoff volume by $20900 \mathrm{cf}(27.0 \%)$. According to the literature reviews shown in Table 17, the peak flow reduction ranged from 18 to 45 percent, and runoff volume reduction ranged from 25-90.

Compared to the peak flow and total volume reductions reported in the literature, the PPs performance simulated by this study for both peak flow and total runoff volume reduction were consistent with the reduction rates from the literature. 
Table 20 The runoff and total inflow of the current site condition (Current for SA) and proposed site condition (Isolated LID)

\begin{tabular}{|l|c|c|}
\hline \multicolumn{3}{|c|}{ From 2/25/2018 1:14:36 AM to 4/8/2018 10:15:24 PM (42.88 days) } \\
\hline & J-SA Isolated LID & J-SA Sewershed_3 Current for SA \\
\hline Maximum Total inflow (cfs) & 1.227 & 1.819 \\
\hline Minimum Total inflow (cfs) & 0 & 0 \\
\hline Mean Total inflow (cfs) & 0.01676 & 0.02677 \\
\hline Duration of Exceedances (h) & 935.5 & 840 \\
\hline Duration of Deficits $(\mathrm{h})$ & 866.7 & 7.983 \\
\hline Number of Exceedances & 1 & 1 \\
\hline Number of Deficits & 12 & 80940 \\
\hline Volume of Exceedances $\left(\mathrm{ft}^{3}\right)$ & 56450 & 0 \\
\hline Volume of Deficits $\left(\mathrm{ft}^{3}\right)$ & 0 & 80940 \\
\hline Total Total inflow $\left(\mathrm{ft}^{3}\right)$ & 56450 & 1 \\
\hline
\end{tabular}

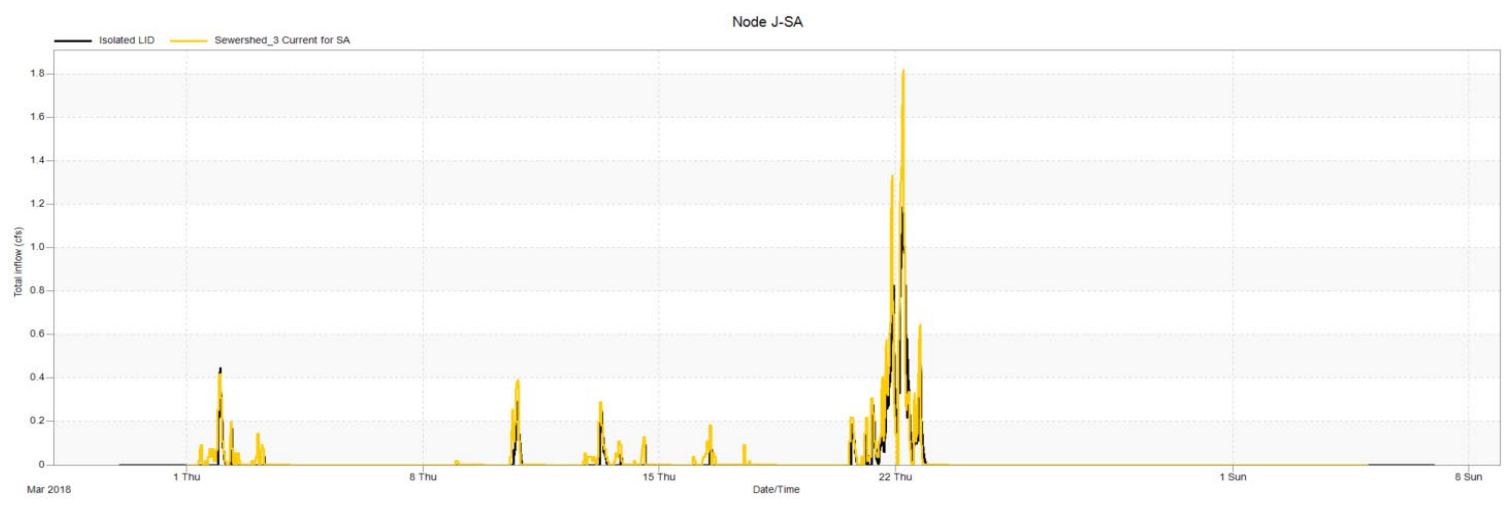

Figure 34 The runoff and total inflow of the current site condition (Current for SA) and proposed site condition (Isolated LID)

Table 21 The table of the inflow (S-SA) and outflow (S-SA-1) through the PPs

\begin{tabular}{|l|c|c|}
\hline \multicolumn{3}{|c|}{ From 2/25/2018 1:14:36 AM to 4/8/2018 10:15:24 PM (42.88 days) } \\
\hline & S-SA & S-SA-1 \\
\hline Maximum Runoff (cfs) & 1.648 & 1.227 \\
\hline Minimum Runoff (cfs) & 0 & 0 \\
\hline Mean Runoff (cfs) & 0.02297 & 0.01676 \\
\hline Duration of Exceedances (h) & 935.5 & 935.5 \\
\hline Duration of Deficits (h) & 797.7 & 866.9 \\
\hline Number of Exceedances & 1 & 1 \\
\hline Number of Deficits & 26 & 12 \\
\hline Volume of Exceedances ( $\mathrm{ft}^{3}$ ) & 77360 & 56440 \\
\hline Volume of Deficits ( $\mathrm{ft}^{3}$ ) & 0 & 0 \\
\hline Total Runoff ( $\mathrm{ft}^{3}$ ) & 77360 & 56440 \\
\hline
\end{tabular}




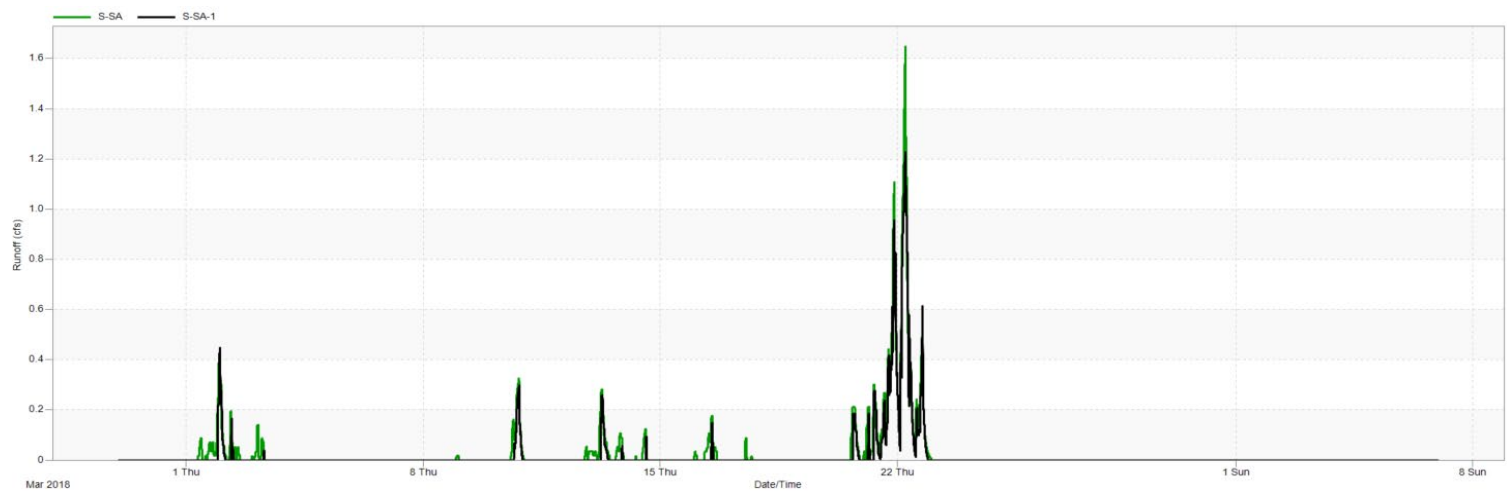

Figure 35 The graph of the inflow (S-SA) and outflow (S-SA-1) through the PPs 


\section{Conclusions and Recommendations}

The study results indicate this stormwater management model for Cal Poly campus has been successfully developed. The LID simulations reveal the effectiveness of the BRC and PPs by reducing peak flow and total runoff volume. Besides, the space for improving this model is still existed and will be discussed in this chapter.

\subsection{Conclusions}

A stormwater model that simulates hydrology of Cal Poly's drainage system has been developed in this study. The model development process involved numerous processes starting from a DWG file that contains utility data all the way to creating a full-watershed scale model that represents the hydrology of Cal Poly campus. The PCSWMM based model can simulate runoff during different rain events, can predict potential flooding, and can analyze the hydrologic performance of various stormwater management practices. The model was calibrated using the streamflow data collected in this study data. Even though the calibration effort significantly improved the prediction accuracy of the model, the data used for the calibration was not adequate implying that there is room to improve the model. Installing a stream gauge or simply collecting streamflow data more consistently during rain events, for example using graduate students, would help with this effort.

In addition to helping with the traditional flood control issues, the model can provide useful information for future planning purposes including potential locations of LIDs, optimal type and size of LIDs to be used, and meeting certain 
stormwater performance targets cost-effectively. To illustrate the benefit of the model in this regard, the model was used to analyze the hydrologic performance of using BRCs and PPs for two planned developments on Cal Poly campus (i.e., Engineering Project Facilities and Freshmen Students Apartment).

The analysis showed that both the BRCs and PPs decreased peak flow and total runoff volume in different degrees under all four scenarios. Also, the simulation results indicated that the LIDs were effective for low-intensity rain events but may not be very effective during heavy rain events. Additionally, the LID performance can be improved by increasing the size of the LID devices since the contributing area was large compared with to the LID size in this study. High total runoff volume reduction was observed even if the contributing area was large compared to the LID area. The LID area was $14.5 \%$ and $0.98 \%$ of the surface area for the site of the engineering project facilities and the new student housing, respectively. By increasing the size of the LIDs, peak flow and total runoff volume reduction rate can be further improved.

In summary, the BRC system used for the engineering project facilities performed better than the same size of the PP system; however, the PP system used for the new student housing performed better than the same size of the BRC system. For the analysis for both LID types on these two sites, a BRC system is recommended to use for the engineering project facilities site and a PP system for the new student housing site. It is recommended to perform further 
analysis on more LID options before making any final decision on which type of LID should be implemented.

\subsection{Limitations}

The following limitations were identified in the process of developing the model.

- The accuracy of the utility data: As previously described, some pipes seemed to be misplaced or are missing. Some pipes do not have outlets, and some have neither inlets nor outlets. In addition, few pipes were missing pipe diameters. Rim and invert elevations were missing for all manholes and inlets. Although workaround was designed to estimate the missing information, the estimates could be different from the reality and lead to erroneous model.

- The lack of information for the storage units: Another uncertainty was lack of reliable bathymetric information for the storage units. Four reservoirs and two dry ponds were located within the San Luis Obispo Creek watershed, the storage curve for the two dry ponds was estimated from the topographic map while the approach was deemed unsuitable for the reservoirs. As a result, the storage curves estimated for the reservoirs were questionable.

- The low resolution of the imperviousness data from USGS: The imperviousness data obtained from the USGS does not seem to accurately represent the percentage of imperviousness in the study area very accurately due to the low resolution of the data. As shown in Table 22 , the highest percent imperviousness is 39.15 percent for 
subcatchment SUB3001. From Google Earth, there are subcatchments with percent imperviousness as high as 60 percent. Further verification of the imperviousness using other sources could improve the accuracy of the model.

- Limited streamflow data was collected for calibration: Only 6 data points were obtained during the streamflow monitoring. This data is not satisfactory to calibrate the model. Additional streamflow data could significantly improve the accuracy of the model.

- The seepage rate of the native soils is unknown: The soil seepage rate at the proposed project sites is unknown. The geotechnical reports available for the proposed sites do not have seepage information. The default seepage rate in PCSWMM was used for all the LID designs in this study.

Table 22 The top four subcatcments with the highest percent imperviousness

\begin{tabular}{|c|c|c|c|c|c|c|c|c|c|c|c|}
\hline \multicolumn{12}{|c|}{ Subcatchments } \\
\hline & Name & X-Coordinate & Y-Coordinate & Tag & $\begin{array}{l}\text { Rain } \\
\text { Gage }\end{array}$ & Outlet & $\begin{array}{c}\text { Area } \\
\text { (ac) }\end{array}$ & $\begin{array}{l}\text { Width } \\
\text { (ft) }\end{array}$ & $\begin{array}{l}\text { Flow } \\
\text { Length } \\
\text { (ft) }\end{array}$ & $\begin{array}{c}\text { Slope } \\
(\%)\end{array}$ & $\begin{array}{c}\text { Imperv. } \\
(\%)\end{array}$ \\
\hline \multirow[t]{4}{*}{ • } & SUB3001 & 5767649.514 & 2304935.376 & WDT & Raingage & OF3001 & 5.6298 & 810.547 & 302.554 & 3.815 & 39.15 \\
\hline & SUB88001 & 5766985.022 & 2305179.932 & WDT & Raingage & JUC88001 & 0.1322 & 53.142 & 108.363 & 2.788 & 37.217 \\
\hline & SUB3002 & 5768147.56 & 2304790.636 & WDT & Raingage & JUC3002 & 8.2438 & 772.298 & 464.976 & 5.435 & 37.14 \\
\hline & SUB49001 & 5766202.579 & 2304436.316 & WDT & Raingage & OF49001 & 16.482 & 1282.231 & 559.927 & 3.525 & 33.586 \\
\hline
\end{tabular}




\subsubsection{Recommendations for Future Research}

Recommendations to improve the developed model are as follows.

- Many model parameters such as the Manning roughness values for conduits, Manning's n value for subcatchments, and the depth of depression storage were taken from the literature. More detailed research could improve these values.

- Field surveys could help to confirm actual watershed boundaries.

Rodriguez, Bocher, \& Chancibault (2013) revealed the importance of conducting field observation to determine a watershed's boundary. For their study area, the watershed boundary changed significantly following the field survey. However, due to the limited time and available resource field observation to define the actual watershed boundary was not deemed realistic in this study. Automated watershed delineation with adjustment using Google Earth was performed.

- The accuracy of the watershed delineation process could be improved if actual manhole/inlet depths were available. To find out the depth of each manhole and inlet, the original construction plans could be reviewed (if available). Additionally, streets should be considered in the delineation process since streets drain runoff into storm inlets.

- Better resolution percent imperviousness data would improve imperviousness values estimated for the subcatchments.

- Not having enough streamflow data is one of the main limitations that need to be resolved to calibrate the SWMM model more properly. Ideally, installing a stream gauge in one of the streams within San Luis Obispo 
Creek watershed would resolve the problem. Alternatively, taking occasional measurements during rain events could be a good alternative.

- More comprehensive site survey to confirm the locations and attributes of pipes, inlets, and manholes would be very beneficial. Construction documents can be reviewed to determine the cover depth of the pipes and manhole depths

- Testing percolation rate of native soils for the proposed project sites would improve the accuracy of the LID simulations. 


\section{Bibliography}

Aad, M. P., Suidan, M. T., \& Shuster, W. D. (2010). Modeling Techniques of Best Management Practices: Rain Barrels and Rain Gardens Using EPA SWMM5. Journal of Hydrologic Engineering, 15(6), 434-443. doi:10.1061/(ASCE)he.1943-5584.0000136

Atchison, D., Potter, K. W., \& Severson, L. (2006). Design guidelines for stormwater bioretention facilities. Madison, WI: Water Resources Institute.

Barber, M. E., King, S. G., Yonge, D. R., and Hathhorn, W. E. (2003). "Ecology ditch: A best management practice for storm water runoff mitigation." J. Hydrol. Eng., 8(3), 111-122.

Barich, J. M. (2014). Sensitivity of Stormwater Management Solutions to Spatial Scale.

Bean, E. Z. (2005). A field study to evaluate permeable pavement surface infiltration rates, runoff quantity, runoff quality, and exfiltrate quality.

Booth, D. B., \& Leavitt, J. (1999). Field Evaluation of Permeable Pavement Systems for Improved Stormwater Management. Journal of the American Planning Association, 65(3), 314-325. doi:10.1080/01944369908976060

Brattebo, B. O., \& Booth, D. B. (2003). Long-term stormwater quantity and quality performance of permeable pavement systems. Water Research, 37(18), 43694376.

Cal Poly (2015). Water quality management plan for Cal Poly land in San Lus Obispo Creek and Chorro Creek Watershed.

Castleton, H., Stovin, V., Beck, S., \& Davison, J. (2010). Green roofs; building energy savings and the potential for retrofit. Energy and Buildings, 42(10), 15821591. doi:10.1016/j.enbuild.2010.05.004

Chen, M., \& Tucker, C. (2003). Comparing different approaches of catchment delineation.

City of San Luis Obispo (n.d.). Sewer Lateral Pipe Material. Retrieved May 14, 2018, from http://www.slocity.org/government/department-directory/utilitiesdepartment/wastewater/wastewater-collections/sewer-lateral-pipe-material/

Collins, K. A., Hunt, W. F., \& Hathaway, J. M. (2008). Hydrologic Comparison of Four Types of Permeable Pavement and Standard Asphalt in Eastern North Carolina. Journal of Hydrologic Engineering, 13(12), 1146-1157.

doi:10.1061/(ASCE)1084-0699(2008)13:12(1146)

Davis, A. P. (2008). "Field performance of bioretention: Hydrology impact." J. Hydrol. Eng., 13(2), 90-95.

Davis, A. P. (2008). Field performance of bioretention: Hydrology impacts. Journal of Hydrologic Engineering, 13(2), 90-95. 
Davis, A. P., Hunt, W. F., Traver, R. G., \& Clar, M. (2009). Bioretention technology: Overview of current practice and future needs. Journal of environmental engineering, 135(3), 109-117.

Davis, A. P., Traver, R. G., Hunt, W. F., Lee, R., Brown, R. A., \& Olszewski, J. M. (2011). Hydrologic performance of bioretention storm-water control measures. Journal of Hydrologic Engineering, 17(5), 604-614.

Dietz, M. E., \& Clausen, J. C. (2005). A Field Evaluation of Rain Garden Flow and Pollutant Treatment. Water, Air, and Soil Pollution, 167(1-4), 123-138. doi:10.1007/s11270-005-8266-8

Dussaillant, A. R., Wu, C. H., \& Potter, K. W. (2004). Richards Equation Model of a Rain Garden. Journal of Hydrologic Engineering, 9(3), 219-225. doi:10.1061/(ASCE)1084-0699(2004)9:3(219)

Elliott, A., \& Trowsdale, S. A. (2007). A review of models for low impact urban stormwater drainage. Environmental modeling \& software, 22(3), 394-405.

EPA, U. (2000). Low Impact Development (LID): a literature review. Washington, DC, US Environmental Protection Agency, Office of Water and Low Impact Development Center.

Fletcher, T., Andrieu, H., \& Hamel, P. (2013). Understanding, management, and modeling of urban hydrology and its consequences for receiving waters: A state of the art. Advances in water resources, 51, 261-279.

Greenberg, S. S. E. (2015). Urban Hydrological Modeling of the Malden River Using the Storm Water Management Model (SWMM). Massachusetts Institute of Technology,

Harrelson, C. C., Rawlins, C. L., \& Potyondy, J. P. (1994). Stream channel reference sites.

Hunt, B., Stevens, S., \& Mayes, D. (2002). Permeable pavement use and research at two sites in Eastern North Carolina. In Global Solutions for Urban Drainage (pp. 1-10).

Kong, F., Ban, Y., Yin, H., James, P., \& Dronova, I. (2017). Modeling stormwater management at the city district level in response to changes in land use and low impact development. Environmental Modelling \& Software, 95, 132-142. doi:https://doi.org/10.1016/j.envsoft.2017.06.021

L, R., \& Huber, W. (2016). Storm Water Management Model Reference Manual Volume III - Water Quality. Retrieved September 27, 2018, from https://nepis.epa.gov/Exe/ZyPDF.cgi/P100P2NY.PDF?Dockey=P100P2NY.PDF

Lau, T., \& Afshar, N. (2013). Effect of roughness on Discharge. UNIMAS ejournal of civil engineering, 4(3).

McCollum, A. R. (2017). Urban Hydrology Stormwater Model. Retrieved December 3, 2018. 
Muleta, M. K., McMillan, J., Amenu, G. G., \& Burian, S. J. (2012). Bayesian approach for uncertainty analysis of an urban storm water model and its application to a heavily urbanized watershed. Journal of Hydrologic Engineering, 18(10), 1360-1371.

NRCS. (2007, April). Rain Gardens. Retrieved October 12, 2018, from https://www.nrcs.usda.gov/Internet/FSE_PLANTMATERIALS/publications/ndpmc tn7278.pdf

Palla, A., \& Gnecco, I. (2015). Hydrologic modeling of Low Impact Development systems at the urban catchment scale. Journal of Hydrology, 528, 361-368.

Parece, T. E., \& Campbell, J. B. (2015). Identifying Urban Watershed Boundaries and Area, Fairfax County, Virginia. Photogrammetric Engineering \& Remote Sensing, 81(5), 365-372.

PCSWMM. (n.d.). Determining the LID clogging factor. Retrieved December 10, 2018, from Determining the LID clogging factor

PCSWMM. (n.d.). Error functions. Retrieved November 12, 2018, from https://support.chiwater.com/79652/error-functions

PCSWMM. (n.d.). Estimating the LID drain coefficient. Retrieved October 28, 2018, from https://support.chiwater.com/83629/estimating-the-lid-drain-coefficient

PCSWMM. (n.d.). Troubleshooting SWMM5 results. Retrieved May 11, 2018, from https://support.chiwater.com/77638/troubleshooting-swmm5-results

Rodriguez, F., Bocher, E., \& Chancibault, K. (2013). Terrain representation impact on periurban catchment morphological properties. Journal of Hydrology, 485, 54-67.

Rossman, L., \& W. Huber, W.C. (2016). Storm Water Management Model Reference Manual Volume III - Water Quality. US EPA Office of Research and Development, Washington, DC, EPA/600/R-16/093, 2016.

Sudha, M., Ragini, M., Shabnam, A., \& Mishra, I. K. (2012). Impact of urbanization on environment. Asian Journal of Environmental Science, 7(2), 235238.

Tikkanen, H. (2013). Hydrological modeling of a large urban catchment using a stormwater management model (SWMM).

U.S. Army Corps of Engineers, Hydrologic Engineering Center. (2009, May). HEC-GeoHMS Geospatial Hydrologic Modeling Extension. Retrieved November 26, 2018, from http://www.hec.usace.army.mil/software/hecgeohms/documentation/HEC-GeoHMS_Users_Manual_4.2.pdf

University of New Hampshire Stormwater Center (UNHSC). (2006). 2005 Data Rep., CICEET, Durham, N.H. 
USDA. (1986, June). Urban Hydrology for Small Watersheds. Retrieved November 12, 2018, from

https://www.nrcs.usda.gov/Internet/FSE_DOCUMENTS/stelprdb1044171.pdf

Virginia DEQ. (2011, March 1). VIRGINIA DEQ STORMWATER DESIGN SPECIFICATION No. 7. Retrieved from

https://www.vwrrc.vt.edu/swc/NonPBMPSpecsMarch11/VASWMBMPSpec7PER MEABLEPAVEMENT.html

Wilson, B., Barfield, B., Ward, A., \& Moore, I. (1984). A hydrology and sedimentology watershed model. Part I: Operational format and hydrologic component. Transactions of the ASAE, 27(5), 1370-1377.

Zaghloul, N., \& Kiefa, M. A. (2001). Neural network solution of inverse parameters used in the sensitivity-calibration analyses of the SWMM model simulations. Advances in Engineering Software, 32(7), 587-595.

Zoppou, C. (2001). Review of urban storm water models. Environmental Modelling \& Software, 16(3), 195-231. 